\title{
Risk Analysis of Air Pollution and Meteorological Factors Affecting the Incidence of Diabetes in the Elderly Population in Northern China
}

\author{
Yao Lin, ${ }^{1}$ Saijun Zhou, ${ }^{1}$ Hongyan Liu, ${ }^{1}$ Zhuang Cui, ${ }^{2}$ Fang Hou, ${ }^{3}$ Siyuan Feng, ${ }^{2}$ \\ Yourui Zhang, ${ }^{3}$ Hao Liu, ${ }^{3}$ Chunlan Lu, ${ }^{3}$ and Pei Yu ${ }^{1}{ }^{1}$ \\ ${ }^{1}$ NHC Key Laboratory of Hormones and Development, Tianjin Key Laboratory of Metabolic Diseases, Chu Hsien-I Memorial \\ Hospital \& Tianjin Institute of Endocrinology, Tianjin Medical University, Tianjin 300134, China \\ ${ }^{2}$ Department of Epidemiology and Health Statistics, Tianjin Medical University, Heping District, Tianjin, China \\ ${ }^{3}$ Community Health Service Center, Jiefang Road, Tanggu Street, Binhai New District, Tianjin, China
}

Correspondence should be addressed to Pei Yu; yupei@tmu.edu.cn

Received 21 April 2020; Revised 23 June 2020; Accepted 14 July 2020; Published 20 October 2020

Academic Editor: Hiroshi Okamoto

Copyright ( 92020 Yao Lin et al. This is an open access article distributed under the Creative Commons Attribution License, which permits unrestricted use, distribution, and reproduction in any medium, provided the original work is properly cited.

\begin{abstract}
Background. Research investigating the effect of air pollution on diabetes incidence is mostly conducted in Europe and the United States and often produces conflicting results. The link between meteorological factors and diabetes incidence remains to be explored. We aimed to explore associations between air pollution and diabetes incidence and to estimate the nonlinear and lag effects of meteorological factors on diabetes incidence. Methods. Our study included 19,000 people aged $\geq 60$ years from the Binhai New District without diabetes at baseline. The generalized additive model (GAM) and the distributed lag nonlinear model (DLNM) were used to explore the effect of air pollutants and meteorological factors on the incidence of diabetes. In the model combining the GAM and DLNM, the impact of each factor (delayed by 30 days) was first observed separately to select statistically significant factors, which were then incorporated into the final multivariate model. The association between air pollution and the incidence of diabetes was assessed in subgroups based on age, sex, and body mass index (BMI). Results. We found that cumulative RRs for diabetes incidence were 1.026 (1.011-1.040), 1.019 (1.012-1.026), and 1.051 (1.019-1.083) per $10 \mu \mathrm{g} / \mathrm{m}^{3}$ increase in $\mathrm{PM}_{2.5}, \mathrm{PM}_{10}$, and $\mathrm{NO}_{2}$, respectively, as well as $1.156(1.058-1.264)$ per $1 \mathrm{mg} / \mathrm{m}^{3}$ increase in CO in a single-pollutant model. Increased temperature, excessive humidity or dryness, and shortened sunshine duration were positively correlated with the incidence of diabetes in single-factor models. After adjusting for temperature, humidity, and sunshine, the risk of diabetes increased by $9.2 \%$ (95\% confidence interval (CI):2.1\%-16.8\%) per $10 \mu \mathrm{g} / \mathrm{m}^{3}$ increase in $\mathrm{PM}_{2.5}$. We also found that women, the elderly ( $\geq 75$ years), and obese subjects were more susceptible to the effect of $\mathrm{PM}_{2.5}$. Conclusion. Our data suggest that $\mathrm{PM}_{2.5}$ is positively correlated with the incidence of diabetes in the elderly, and the relationship between various meteorological factors and diabetes in the elderly is nonlinear.
\end{abstract}

\section{Introduction}

Diabetes is one of the top ten reasons for increases in Years Lived with Disability (YLD) and exacerbates the global burden of disease [1]. More than $80 \%$ of diabetes deaths occur in low- and middle-income countries, and China has the highest diabetes prevalence $[2,3]$. Therefore, it is essential to predict diabetes incidence accurately and to control its possible risk factors. It has been widely recognized that fam- ily history, age, obesity, and genetic susceptibility are all risk factors for diabetes, and recent evidence supports the hypothesis that air pollution might be an essential risk factor for diabetes. Since most risk factors are uncontrollable, air pollution acting as an intervening factor may provide a turning point for the prevention of diabetes and reduce the heavy burden caused by this condition [4-8].

Suspended particulate matter (PM) and gaseous pollutants such as ozone $\left(\mathrm{O}_{3}\right)$, nitrogen dioxide $\left(\mathrm{NO}_{2}\right)$, carbon 
monoxide $(\mathrm{CO})$, and sulfur dioxide $\left(\mathrm{SO}_{2}\right)$ are major air pollutants posing a threat to human health. Previous research has shown that exposure to $\mathrm{PM}_{2.5}$ may increase the risk of diabetes or death due to diabetes [9-11]. Possible mechanisms behind this increased risk include oxidative stress, systemic inflammation, immune response, insulin resistance, disorders of the autonomic nervous system, and alterations of mitochondrial function and gene expression in adipose tissue [12]. Air pollution possibly acts through pathways that affect glucose homeostasis, thereby increasing the risk of diabetes [13-15].

In addition to air pollutants, meteorological factors are also closely related to human health, and the effects of climate change have a disproportionate impact on the health of vulnerable groups in low- and middle-income countries [16]. There are close connections between meteorological factors and noncommunicable diseases, such as cardiovascular, respiratory, and metabolic diseases [17-19]. A few of these studies explored the association between meteorological factors and diabetes and found that extreme temperatures increase diabetes mortality and hospitalization rates and affect glucose homeostasis. Additionally, sunshine can reduce the incidence of diabetes [20-23]. However, studies on other meteorological factors, such as humidity, wind speed, and precipitation, are rare.

Although evidence of air pollution, especially PM, is increasing, diabetes-related results to guide the establishment of air quality standards remain controversial. Furthermore, most studies are conducted in developed countries, and there is a lack of evidence from developing countries in Asia. However, the estimated prevalence of diabetes among adults in China was $10.9 \%$ in 2013 [24]. The prevalence was higher in rural Tianjin than in the overall Chinese rural and urban population, according to the Fourth National Nutritional Survey [25]. China is a developing country with the largest population in the world. With rapid urbanization and industrialization, the burning of large amounts of fuel and the emission of vehicle exhausts have resulted in decreased air quality [26]. The most polluted cities are mainly located in North China Plain, which includes Tianjin [27]. With the implementation of the Air Pollution Prevention Action Plan, which was the most stringent air pollution plan to date in China, the concentrations of $\mathrm{SO}_{2}, \mathrm{NO}_{2}, \mathrm{PM}_{10}$, and $\mathrm{PM}_{2.5}$ decreased in Tianjin from 2012 to 2017, but still exceeded the national standard air quality index (AQI) level II and far exceeded the WHO guidelines. Air pollution caused significant public health problems, affecting over 100 million people in the Beijing-Tianjin-Hebei (BTH) region [28]. Given the heavy burden of diabetes and the inevitable exposure to air pollution, the association between air pollution and diabetes may have clinical and public health significance, especially in Tianjin, China. Meteorological factors are also risk factors for diabetes, and there are interactions or synergies between meteorological factors and air pollutants [29]. However, studies about the impact of meteorological factors on diabetes incidence are limited, and results are inconsistent due to differences in geographic locations and races studied. Therefore, an evaluation of the relationship between meteorological factors and diabetes is urgently warranted. The pur- pose of this study was to investigate the effects of air pollutants and meteorological factors on the incidence of diabetes to provide theoretical support and reference for environmental management as well as to relieve the burden of diabetes.

\section{Material and Methods}

2.1. Study Population and Area. The Binhai New District (east longitude 117.68, north latitude 39.03) is located in the Eastern coastal area of Tianjin. It is the center of the Bohai Economic Circle, with a total area of 2,270 square kilometers and a population of 2.97 million. We included residents aged 60 years and older who regularly participated in free medical examinations in Tianjin Binhai New District. A total of 37 community hospitals were involved, covering approximately 360,000 people. After screening the data, subjects with diabetes at baseline, residents under the age of 60 , and residents with repeated physical examinations within one year were excluded. This resulted in a total of 190,453 people included in this study.

2.2. Health Data. The daily incidence of diabetes in Tianjin Binhai New District from January 1, 2014, to December 31, 2017, was obtained from the Tianjin Community Health Service Information System (http://218.68.9.122:808/), an official website for collecting and registering basic information and medical examination data for residents aged $\geq 60$ years in Tianjin. Residents from 37 community hospitals in Tianjin Binhai New District participated for free in the annual medical examinations. In addition to the date of diagnosis and incidence of diabetes, the trained doctors also collected biochemical test values, including triglycerides, cholesterol, serum urea nitrogen, serum creatinine, aspartate aminotransferase, alanine aminotransferase, fasting blood glucose, hemoglobin, platelets, and white blood cells. The following demographic characteristics and behavioral health data were also collected by a face-to-face conversation on the day of medical examinations: gender, age, weight, height, body mass index (BMI), smoking status, drinking status, and exercise frequency. Finally, the above information was electronically recorded. The diseases in this study were coded according to The International Classification of Diseases, Revision 10 (ICD-10). The crude rate of diabetes diagnosed in community hospitals was 3.7 per 1,000 person-years, and additional patients were diagnosed in higher-level hospitals. Finally, the data were screened by ID card number, a unique number for national legal identity, to ensure that there were no duplications.

2.3. Diagnosis of Diabetes. We defined a new-onset diabetes event as a patient who was without diabetes on January 1, 2014 , and then diagnosed with diabetes during the study. Diabetes was diagnosed based on the criteria of the WHO Diabetes Committee in 1999. Diagnosis of diabetes included the following: diagnosed as diabetes by medical personnel or self-reported diagnosis of diabetes in hospital (ICD-10 code: E10-E14); taking antidiabetic drugs or subcutaneous insulin therapy within the 12 months before the medical examination; 
or diagnosed by medical personnel and recommended for diabetes diet and physical activity programs. Although we cannot rule out type 1 diabetes, considering that on average $>90 \%$ of adult diabetes is type 2 diabetes and our research was aimed at elderly aged $\geq 60$ years, it can be assumed that most cases were type 2 diabetes [30]. All subjects who met the above diagnostic criteria for diabetes at baseline (January 1, 2014) were considered preexisting diabetes patients and were excluded from the study.

2.4. Air Pollution Data. According to the National Environmental Protection Standard of the People's Republic of China (http://www.mee.gov.cn/GB3095-2012), real-time air quality is measured every hour by the four Air Quality Monitoring (AQM) stations located in Binhai New District and data of particulate pollutants $\left(\mathrm{PM}_{2.5}\right.$ and $\left.\mathrm{PM}_{10}\right)$ and gaseous pollutants $\left(\mathrm{NO}_{2}, \mathrm{SO}_{2}, \mathrm{CO}\right.$, and $\left.\mathrm{O}_{3}\right)$ are recorded. We downloaded data of air pollutants from January 1, 2014, until December 31, 2017, from the website of the Tianjin Ecological Environment Monitoring Center (http://www.tjemc.org.cn/index .html) and calculated the arithmetic mean of air pollutants concentrations for every 24 hours, except for $\mathrm{O}_{3}$, which was calculated as a daily 8-hour maximum $\mathrm{O}_{3}$ concentration, as the daily average concentration of air pollutants at each monitoring point. An average of these four monitoring stations' concentrations of air pollutants was used as the daily average concentration of air pollutants in Binhai New District. The average concentration of air pollutants within a day was calculated only when there were more than 20 valid data. Before calculating the average concentrations, the hourly data of each station were checked for soundness to remove the nonconforming data by the "is.na" function.

2.5. Meteorological Data. All meteorological factors were measured eight times per day, at local time of $02,05,08,11$, $14,17,20$, and 23 hours. These measurements were used to calculate the daily average. Meteorological data were downloaded from the China Meteorological Data Sharing Service System (http://data.cma.cn/), including daily average temperature $\left({ }^{\circ} \mathrm{C}\right)$, relative humidity $(\%)$, wind speed $(\mathrm{m} / \mathrm{s})$, atmospheric pressure $(\mathrm{hPa})$, precipitation $(\mathrm{mm})$, and duration of sunshine $(\mathrm{h})$. The average level (mean value) of four monitoring sites in Tianjin Binhai New District was used as the exposure level for residents.

2.6. Statistical Analysis. Correlations between air pollutants and meteorological factors were assessed by the Spearman rank correlation test, and the collinearity between independent variables was examined. Based on experience, the occurrence of diabetes in the population is a small probability event, and the overall distribution of cases is scattered, consistent with the Poisson distribution. Therefore, the Poisson's generalized additive model (GAM) was chosen as the model framework in this study. In view of the existing biological and epidemiological studies, we decided the confounding factors that need to be adjusted (day of the week (DOW), time, and meteorological factors) when focused on air pollution. Because the incidence of diabetes was not only affected by air pollution or meteorological factors of the day, but also related to the exposure levels of the previous few days. In order to fit the nonlinear and delayed effects, we used a distributed lag nonlinear model (DLNM) to construct a "cross-basis" function, a bidimensional function expressed by two basic functions, depicting the effects of predictors and lags simultaneously. The structure of our model for air pollution was as follows:

$$
\begin{aligned}
\operatorname{LogE}(\mathrm{Yt})= & \beta Z_{t, l}+\mathrm{DOW}+\mathrm{ns}(\text { time }, \mathrm{df})+\mathrm{ns}\left(\frac{\text { temperature }}{\cdots}, \mathrm{df}\right) \\
& + \text { intercept }
\end{aligned}
$$

where Yt represented the expected number of diabetes cases; $\beta Z_{t, l}$ represented the cross-basis objects used to estimate the effects of air pollutants; $Z$ was determined by each pollutant $\left(\mathrm{PM}_{2.5}, \mathrm{PM}_{10}, \mathrm{NO}_{2}, \mathrm{SO}_{2}, \mathrm{O}_{3}\right.$, and $\left.\mathrm{CO}\right) ; \beta$ was the coefficient for $Z_{t, l}$, the logarithmic increase in the number of diabetes cases caused by the increase of air pollutant by one unit; $t$ represented the observation day, and $l$ represented the lag days; ns was a natural cubic spline function, and df was its degree of freedom; time was a date variable used to control time trends and seasonal fluctuations; DOW represented the day of the week, controlling the natural fluctuations of the number of people with diabetes in a week; and temperature $/ \cdots$ referred to meteorological conditions, which were used to adjust the impact of meteorological factors on diabetes incidence. To fit the model, we set the $\mathrm{df}$ of natural cubic spline functions for time to 11 per year, which was based on the Akaike information criterion (AIC) and the principle of the partial autocorrelation function (PACF) [31]. And we set the df of meteorological factors to 3, based on experience and previous studies. The model for meteorological factors is shown in the Supplementary Materials (available here).

We first used a single-pollutant model to examine the association between the incidence of diabetes and the exposure of each air pollutant on the day (lag 0 days) to obtain estimated values that were not adjusted for meteorological factors. Additionally, the relationships between meteorological factors (lag 0 days) and diabetes incidence were analyzed. To verify the stability of the association between air pollution and diabetes incidence, a double-pollutant model was constructed. In addition, to avoid underestimating the relationship between air pollutants, meteorological factors, and diabetes, we studied the hysteresis and cumulative effects of air pollutants and meteorological factors on the incidence of diabetes. This allowed for the assessment of the impact of various factors on the occurrence of diabetes over time and the clarification of the duration of each factor's effect. Then, we constructed a three-dimensional model of meteorological factors and diabetes. Based on the single-factor models, statistically significant air pollutants $\left(\mathrm{PM}_{2.5}, \mathrm{NO}_{2}\right.$, and $\mathrm{CO}$ ) were included in the final multivariate model, and relevant meteorological factors (temperature, humidity, and sunshine) were selected as covariates. In the data processing process, we found that sixteen days' data of air pollutants in 2014 were missing, and the "na.approx" function from the 
“zoo" package in R software was used to fill the missing data with linear interpolated values [32].

We performed subgroup analyses of air pollutants, taking the sensitivity to air pollutants of different populations into account. We evaluated possible effect modification of these demographic characteristics, stratifying the population into different groups by sex (male or female), age ( $<75$ or $\geq 75$ years), and BMI $\left(<18.5 \mathrm{~kg} / \mathrm{m}^{2}, 18.5-23.99 \mathrm{~kg} / \mathrm{m}^{2}, 24-27.9 \mathrm{~kg} / \mathrm{m}^{2}\right.$, and $\geq 28 \mathrm{~kg} / \mathrm{m}^{2}$ ).

In all statistical tests, a two-sided $P<0.05$ was considered significant. All analysis was performed in R software, version 3.5.1, and the fitting process was implemented using the "dlnm" and "mgcv" packages. The effect-estimated value is the relative risk ratio (RR) of the onset of diabetes and its $95 \%$ confidence interval (CI) for each $10 \mu \mathrm{g} / \mathrm{m}^{3}, 1 \mathrm{mg} / \mathrm{m}^{3}$, or interquartile range (IQR) increase of the corresponding air pollutant's concentration.

\section{Results}

Finally, 190,453 participants aged $\geq 60$ years in Tianjin Binhai New District were included in the study, and the population characteristics are summarized in Table 1 . The median (interquartile range) age was 68 (64-72) years, and the ratio of male to female was $1: 1.09$. A total of $49.31 \%$ of enrolled participants exercised every day, and $28.05 \%$ of participants never exercised. The participants did not have diabetes at baseline, and the median (interquartile range) value of fasting blood glucose (FBG) was 5.30 (4.91-5.70) mmol/L. During 2014-2017, there were 7,585 new-onset diabetes patients among the 190,453 nondiabetic participants, resulting in a crude incidence of diabetes of 9.9 per 1,000 person-years. There were 4,180 females (55\%), 1,371 subjects aged $\geq 75$ years (18\%), and 5,413 overweight and obese people (71\%) among these new-onset diabetes patients. Figure 1 shows the monthly distribution of new-onset diabetes patients in the study from 2014 to 2017 . The number of new-onset diabetes cases fluctuated to varying degrees every month. From 2014 to 2016, the number of new-onset diabetes had declined, but this rebounded in 2017. In general, diabetes was diagnosed more often in winter and spring (January, March to May), and less in summer (June to July).

Tables 2 and 3 show the statistical summary of air pollutants and meteorological factors. The average concentration of $\mathrm{PM}_{2.5}$ was $70.56 \mu \mathrm{g} / \mathrm{m}^{3}$, which was more than once higher than the national standard $\left(35 \mu \mathrm{g} / \mathrm{m}^{3}\right)$. The average concentrations of $\mathrm{PM}_{10}, \mathrm{SO}_{2}, \mathrm{CO}, \mathrm{O}_{3}$, and $\mathrm{NO}_{2}$ were $96.24 \mu \mathrm{g} / \mathrm{m}^{3}$, $23.55 \mu \mathrm{g} / \mathrm{m}^{3}, \quad 1.42 \mathrm{mg} / \mathrm{m}^{3}, 53.18 \mu \mathrm{g} / \mathrm{m}^{3}$, and $48.2 \mu \mathrm{g} / \mathrm{m}^{3}$, respectively. The corresponding median of the temperature, humidity, sunshine, air pressure, precipitation, and wind speed were $15.4^{\circ} \mathrm{C}, 57 \%, 8 \mathrm{~h}, 1016.6 \mathrm{hPa}, 0 \mathrm{~mm}$, and $2.3 \mathrm{~m} / \mathrm{s}$, respectively.

Figures 2 and 3 show the monthly distribution of each air pollutant and meteorological factor from 2014 to 2017. The $\mathrm{PM}_{2.5}, \mathrm{PM}_{10}, \mathrm{NO}_{2}, \mathrm{SO}_{2}$, and $\mathrm{CO}$ all reached the highest concentration in winter (December-February) and the lowest in summer (June-August), while $\mathrm{O}_{3}$ levels were showing the opposite effect. Temperature and air pressure had apparent seasonal fluctuations, and the temperature was higher in
TABLE 1: The population characteristics at baseline.

\begin{tabular}{lc}
\hline & Median $(\mathrm{P} 25, \mathrm{P} 75)(n=190453)$ \\
Age $($ years $)$ & $68(64,72)$ \\
Weight $(\mathrm{kg})$ & $66(60,73)$ \\
Height $(\mathrm{cm})$ & $165(159,170)$ \\
BMI $\left(\mathrm{kg} / \mathrm{m}^{2)}\right.$ & $24.0(22.6,26.2)$ \\
Waistline $(\mathrm{cm})$ & $84(79,90)$ \\
TG $(\mathrm{mmol} / \mathrm{L})$ & $1.30(1.01,1.71)$ \\
TC $(\mathrm{mmol} / \mathrm{L})$ & $5.04(4.43,5.70)$ \\
BUN $(\mathrm{mmol} / \mathrm{L})$ & $5.40(4.58,6.35)$ \\
Scr $(\mu \mathrm{mol} / \mathrm{L})$ & $73.0(60.8,86.0)$ \\
TB $(\mu \mathrm{mol} / \mathrm{L})$ & $12.7(10.0,16.2)$ \\
AST $(\mathrm{U} / \mathrm{L})$ & $21.0(17.0,26.0)$ \\
ALT $(\mathrm{U} / \mathrm{L})$ & $19.0(14.0,25.0)$ \\
FBG $(\mathrm{mmol} / \mathrm{L})$ & $5.30(4.91,5.70)$ \\
Hemoglobin $(\mathrm{g} / \mathrm{L})$ & $137(128,147)$ \\
\hline & $N(\%)(n=190453)$ \\
Sex, male & $91237(47.91)$ \\
Physical activity &
\end{tabular}

BMI: body mass index; TC: total cholesterol; TG: triglyceride; BUN: blood urea nitrogen; Scr: serum creatinine; TB: total bilirubin; ALT: glutamicpyruvic transaminase; AST: glutamic oxalacetic transaminase; FBG: fasting blood glucose.

summer and lower in winter, which was opposite to the air pressure. The regularity of humidity and precipitation was similar. Wind speed changed with no discernable patterns, but the wind speed was faster in spring (March-May).

Table 4 lists the results of the Spearman correlation between air pollutants and meteorological factors. $\mathrm{PM}_{2.5}$, $\mathrm{PM}_{10}, \mathrm{NO}_{2}, \mathrm{SO}_{2}$, and $\mathrm{CO}$ were positively correlated with each other, with correlation coefficients ranging from 0.548 to 0.897 , while $\mathrm{O}_{3}$ was negatively correlated with all other air pollutants. $\mathrm{O}_{3}$ was positively correlated with all meteorological factors except for atmospheric pressure. Except for $\mathrm{O}_{3}$, all other pollutants were negatively correlated with sunshine duration and positively correlated with atmospheric pressure.

Figure 4 shows the delayed (longest lag 30 days) and the cumulative effect of the association between air pollutants and the onset of diabetes in a single-factor model. 


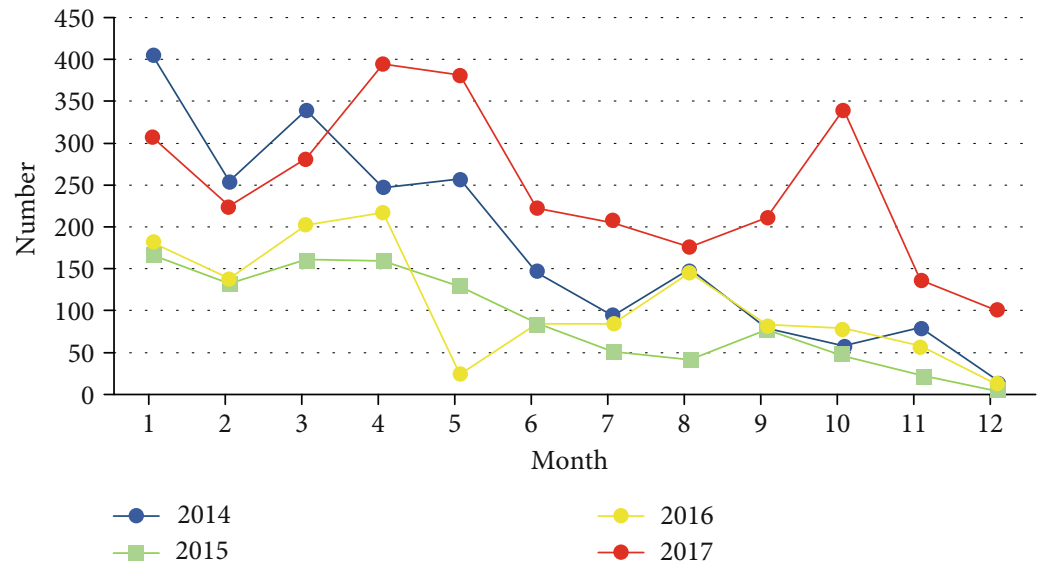

FIgURE 1: Monthly distribution of new-onset diabetes during 2014 to 2017.

Table 2: Air pollutants in Binhai New Area during 2014 to 2017.

\begin{tabular}{lcccccccc}
\hline & Min & 25\% quartile & Median & $75 \%$ quartile & Max & Mean & Standard deviation & Interquartile range \\
\hline $\mathrm{PM}_{2.5}\left(\mu \mathrm{g} / \mathrm{m}^{3}\right)$ & 10.68 & 36.38 & 56.55 & 89.10 & 343.33 & 70.56 & 49.22 & 52.72 \\
$\mathrm{PM}_{10}\left(\mu \mathrm{g} / \mathrm{m}^{3}\right)$ & 11.11 & 64.51 & 96.24 & 142.87 & 975.75 & 96.24 & 72.60 & 78.36 \\
$\mathrm{NO}_{2}\left(\mu \mathrm{g} / \mathrm{m}^{3}\right)$ & 9.18 & 30.44 & 43.78 & 61.91 & 177.77 & 48.20 & 23.50 & 31.47 \\
$\mathrm{SO}_{2}\left(\mu \mathrm{g} / \mathrm{m}^{3}\right)$ & 1.98 & 10.64 & 16.94 & 29.95 & 161.48 & 23.55 & 19.69 & 19.31 \\
$\mathrm{O}_{3}\left(\mu \mathrm{g} / \mathrm{m}^{3}\right)$ & 2.57 & 26.39 & 46.68 & 75.25 & 174.43 & 53.18 & 33.94 & 0.78 \\
$\mathrm{CO}\left(\mathrm{mg} / \mathrm{m}^{3}\right)$ & 0.27 & 0.91 & 1.25 & 1.71 & 9.23 & 1.42 & & 0.80 \\
\hline
\end{tabular}

Table 3: Meteorological factors in Binhai New Area during 2014 to 2017.

\begin{tabular}{lcccccccc}
\hline & Min & $25 \%$ quartile & Median & $75 \%$ quartile & Max & Mean & Standard deviation & Interquartile range \\
\hline Average temperature $\left({ }^{\circ} \mathrm{C}\right)$ & -14.50 & 3.45 & 15.40 & 24.25 & 33.30 & 14.27 & 10.84 & 20.80 \\
Maximum temperature $\left({ }^{\circ} \mathrm{C}\right)$ & -11.30 & 7.80 & 20.30 & 28.50 & 39.33 & 18.58 & 11.07 & 20.70 \\
Humidity (\%) & 13 & 43 & 57 & 72 & 99 & 57 & 18.19 & 29 \\
Precipitation $(\mathrm{mm})$ & 0.00 & 0.00 & 0.00 & 0.00 & 148.30 & 1.52 & 7.14 & 3.94 \\
Sunshine $(\mathrm{h})$ & 0.00 & 4.10 & 8.00 & 10.00 & 13.60 & 6.98 & 10 & 5.90 \\
Average pressure $(\mathrm{hPa})$ & 994 & 1008 & 1017 & 1025 & 1043 & 1017 & 10 & 17 \\
Average wind speed $(\mathrm{m} / \mathrm{s})$ & 0.50 & 1.80 & 2.30 & 3.00 & 9.40 & 2.47 & 0.95 & 1.20 \\
\hline
\end{tabular}

(i) $\mathrm{PM}_{2.5}$ : exposure to $\mathrm{PM}_{2.5}$ increased the incidence of diabetes, and the effect was the strongest on the day and then decayed gradually. By the 25th day, the effect was no longer present, and the cumulative effect also rose within 25 days (Figure 4(a)).

(ii) $\mathrm{PM}_{10}$ : the lag and cumulative effect of $\mathrm{PM}_{10}$ on diabetes incidence were similar to that of the $\mathrm{PM}_{2.5}$. The negative effect was strongest on the day and then gradually decayed until the 25th day. However, compared to $\mathrm{PM}_{2.5}, \mathrm{PM}_{10}$ had a weaker effect on the incidence of diabetes (Figure 4(b)).

(iii) $\mathrm{NO}_{2}$ : there was a positive correlation between $\mathrm{NO}_{2}$ levels and diabetes incidence within 8 days and 2027 days. Although $\mathrm{NO}_{2}$ was also positively correlated with diabetes on days 9-19, the association was not statistically significant. Combined with the cumulative effect curve, exposure to $\mathrm{NO}_{2}$ was associated with an increased incidence of diabetes (Figure 4(c)).

(iv) $\mathrm{SO}_{2}$ : for both the single-effect and the cumulativeeffect curves, no relationship between $\mathrm{SO}_{2}$ and diabetes incidence was found (Figure 4(d)).

(v) $\mathrm{CO}$ : exposure to $\mathrm{CO}$ is a relative risk factor for diabetes within 16 days, after which there was no significant correlation between $\mathrm{CO}$ and diabetes (Figure 4(e)).

(vi) $\mathrm{O}_{3}$ : in the single-effect curve, $\mathrm{O}_{3}$ was negatively correlated with the incidence of diabetes between the 12th day and the 23rd day. The cumulative-effect curve showed that $\mathrm{O}_{3}$ and the incidence of diabetes were negatively correlated from the 5th day (Figure 4(f)). 

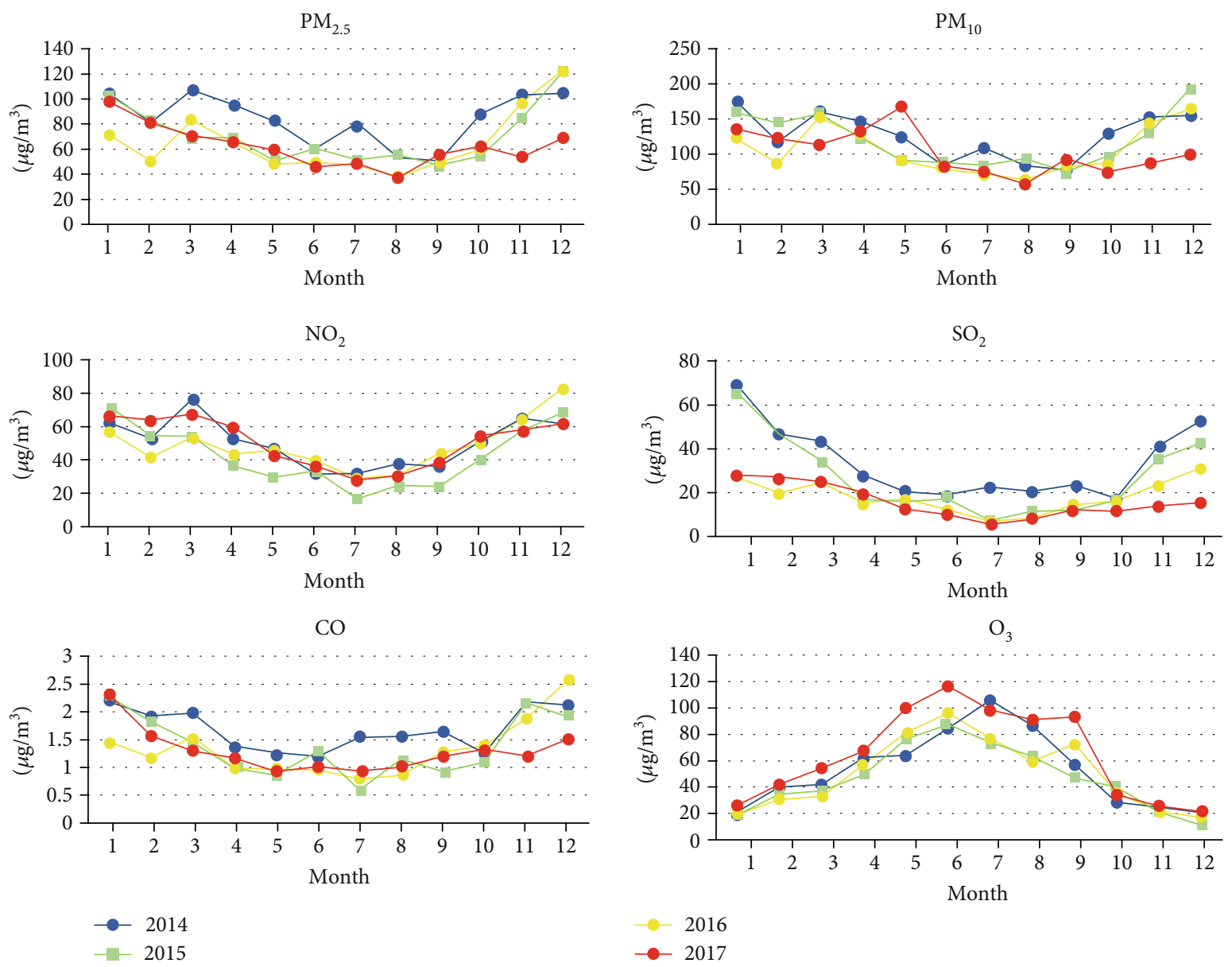

FIGURE 2: Monthly average changes in air pollutants for 2014-2017.

Figure 5 shows the cumulative effect of lag 30 days for each meteorological factor in single meteorological factor models. The cumulative relative risks over 30 lag days of the full range of meteorological factors are presented. The black lines are the effect estimates, and the gray areas are the $95 \%$ CI. The median values were used as the reference for calculating the cumulative effect of various meteorological factors to study the lowest cumulative effect of different meteorological factors. The values of meteorological factors with the lowest cumulative effect value for 30 days were $-14.5^{\circ} \mathrm{C}$ for temperature, $71 \%$ for humidity, $1042.7 \mathrm{hPa}$ for atmospheric pressure, $13.6 \mathrm{~h}$ for the sunshine duration, $0 \mathrm{~mm}$ for precipitation, and $4.5 \mathrm{~m} / \mathrm{s}$ for wind speed. These values were used as references to estimate the effects of meteorological factors on diabetes, as presented in Figures 6 and 7.

The relationship between meteorological factors and the incidence of diabetes was nonlinear. Figure 6 shows threedimensional (3D) graphs distributed in a hexahedron, which vividly depicts the relationship of meteorological factors, lag days, and risk of diabetes incidence (referenced to the values of meteorological factors with the lowest cumulative effect for 30 days). One bottom edge of the hexahedron represents the full range of meteorological factors, the other bottom edge represents the number of days delayed, and the height represents the relative risk of diabetes incidence. The 3D graphics show the impact of different meteorological factor values on the incidence of diabetes when lagging on different days. Figure 7 shows contour plots of various meteorological factors depicting the estimated effects on diabetes incidence of the full range of meteorological factors over different lag days (referenced to the lowest effect value of meteorological factors). It is similar to the plot in Figure 6 and describes the risk of diabetes incidence with color. Blue indicates that the RR value was $<1$, and red indicates an RR value of $>1$. In other words, blue indicates a protective factor, and red indicates a risk factor, and the darker the red color, the higher the risk of diabetes.

(i) Humidity: whether excessively moist or dry, humidity increased the risk of diabetes, and the effect of moisture lasted longer. The humidity in the Binhai New District usually ranged from $43 \%$ to $72 \%$, which meant that an adverse effect on the incidence of diabetes only occurred in extreme weather conditions.

(ii) Sunshine: the shortening of sunshine duration was positively correlated with diabetes incidence, and the correlation was strongest within five days of exposure.

(iii) Atmosphere pressure: the atmospheric pressure fluctuated between 994.2 and $1042.7 \mathrm{hPa}$. The risk 

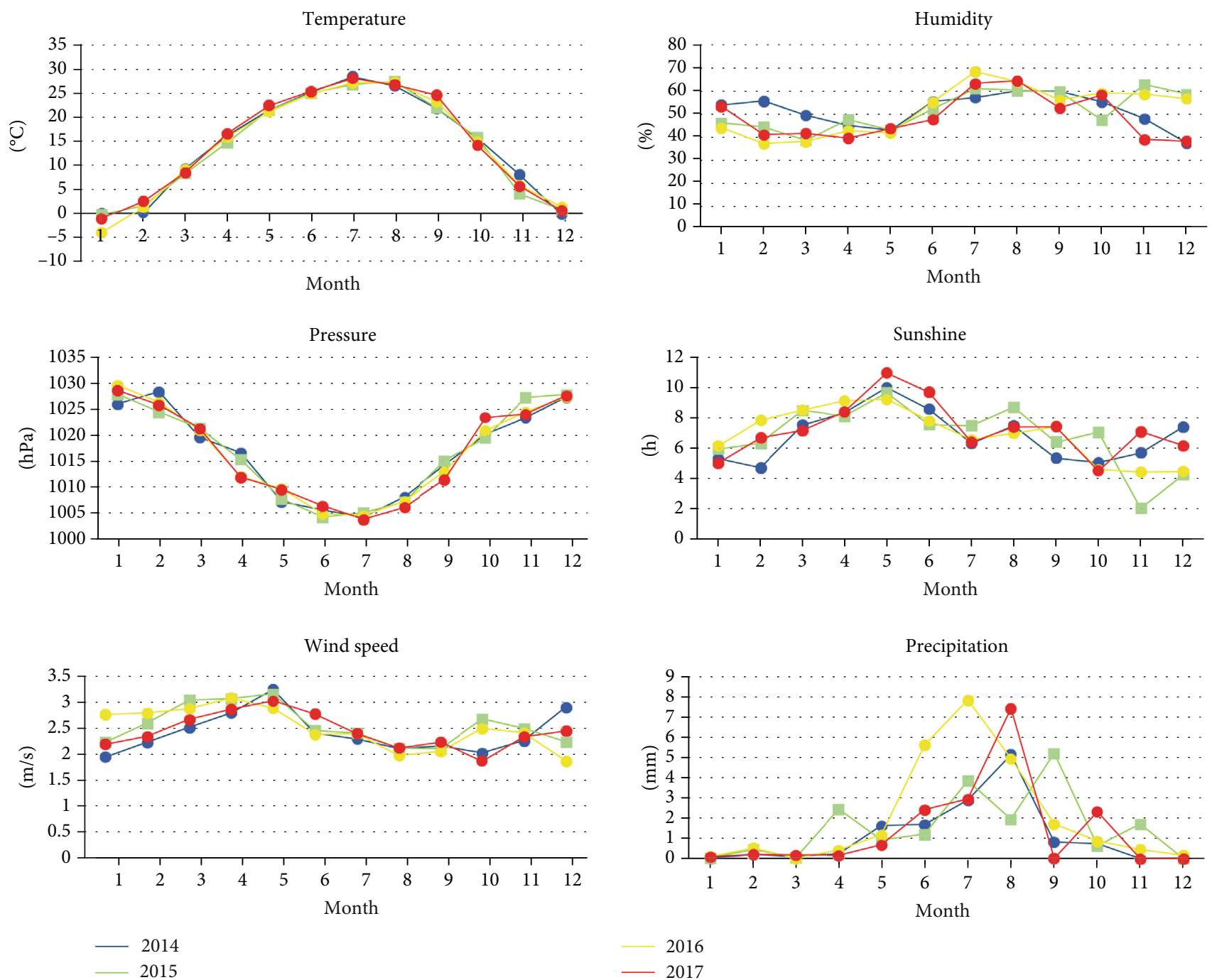

FIGURE 3: Monthly average changes in meteorological factors for 2014-2017.

TABLE 4: Spearman correlation analysis between air pollutants and meteorological variables.

\begin{tabular}{|c|c|c|c|c|c|c|c|c|c|c|c|c|}
\hline & Number & $\mathrm{PM}_{2.5}$ & $\mathrm{PM}_{10}$ & $\mathrm{SO}_{2}$ & $\mathrm{O}_{3}$ & $\mathrm{NO}_{2}$ & $\mathrm{CO}$ & Humidity & Temperature & Precipitation & Sunshine & Pressure \\
\hline $\mathrm{PM}_{2.5}$ & .039 & & & & & & & & & & & \\
\hline $\mathrm{PM}_{10}$ & $.078^{* *}$ & $.897^{* *}$ & & & & & & & & & & \\
\hline $\mathrm{SO}_{2}$ & .024 & $.548^{* *}$ & $.581^{* *}$ & & & & & & & & & \\
\hline $\mathrm{O}_{3}$ & $.148^{* *}$ & $-.228^{* *}$ & $-.228^{* *}$ & $-.449^{* *}$ & & & & & & & & \\
\hline $\mathrm{NO}_{2}$ & $.123^{* *}$ & $.611^{* *}$ & $.611^{* *}$ & $.721^{* *}$ & $-.531^{* *}$ & & & & & & & \\
\hline $\mathrm{CO}$ & .008 & $.657^{* *}$ & $.590^{* *}$ & $.734^{* *}$ & $-.448^{* *}$ & $.688^{* *}$ & & & & & & \\
\hline Humidity & $-.122^{* *}$ & $.265^{* *}$ & .032 & $-.161^{* *}$ & .012 & $-.082^{* *}$ & $.185^{* *}$ & & & & & \\
\hline Temperature & -.031 & $-.122^{* *}$ & $-.162^{* *}$ & $-.509^{* *}$ & $.769^{* *}$ & $-.482^{* *}$ & $-.400^{* *}$ & $.229^{* *}$ & & & & \\
\hline Precipitation & $-.058^{*}$ & $-.151^{* *}$ & $-.259^{* *}$ & $-.302^{* *}$ & $.089^{* *}$ & $-.271^{* *}$ & $-.118^{* *}$ & $.425^{* *}$ & $.151^{* *}$ & & & \\
\hline Sunshine & $.130^{* *}$ & $-.271^{* *}$ & $-.135^{* *}$ & $-.142^{* *}$ & $.425^{* *}$ & $-.216^{* *}$ & $-.331^{* *}$ & $-.539^{* *}$ & $.300^{* *}$ & $-.335^{* *}$ & & \\
\hline Pressure & -.033 & .043 & $.059^{*}$ & $.455^{* *}$ & $-.714^{* *}$ & $.438^{* *}$ & $.341^{* *}$ & $-.234^{* *}$ & $-.886^{* *}$ & $-.216^{* *}$ & $-.252^{* *}$ & \\
\hline Wind speed & $.101^{* *}$ & $-.273^{* *}$ & $-.145^{* *}$ & $-.201^{* *}$ & $.221^{* *}$ & $-.371^{* *}$ & $-.311^{* *}$ & $-.352^{* *}$ & -.004 & -.008 & $.240^{* *}$ & $-.070^{* *}$ \\
\hline
\end{tabular}


$\mathrm{PM}_{2.5}(95 \mathrm{CI})$

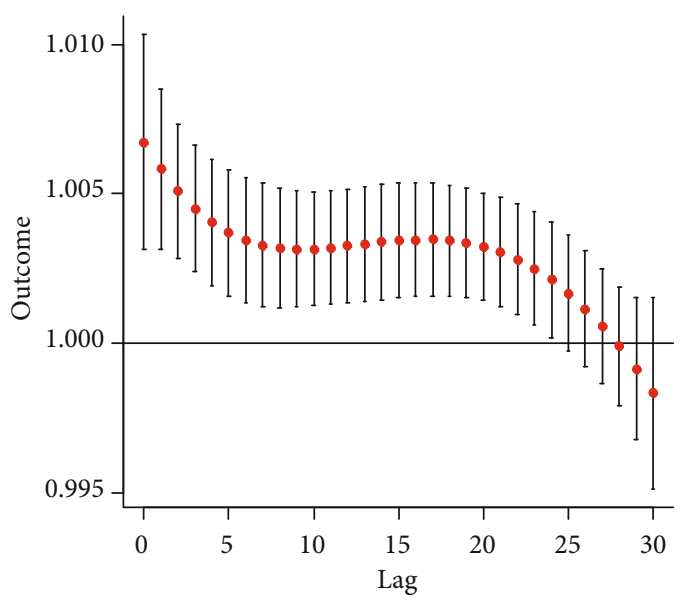

$\mathrm{PM}_{10}(95 \mathrm{CI})$

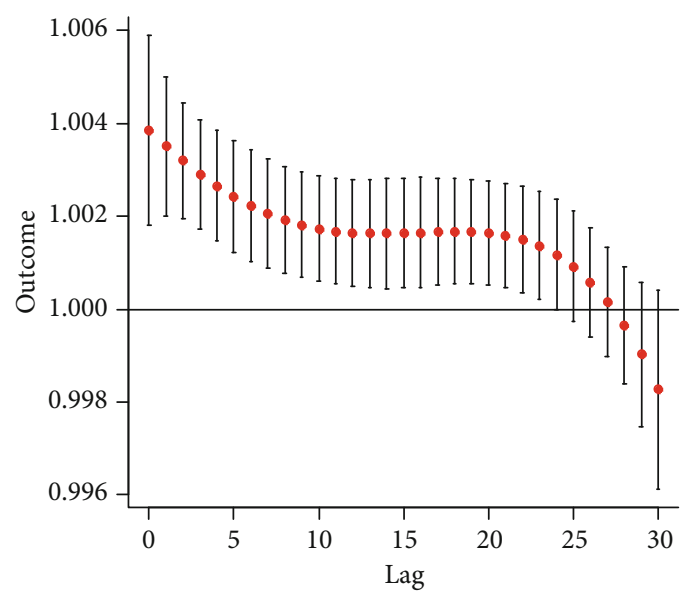

(b)

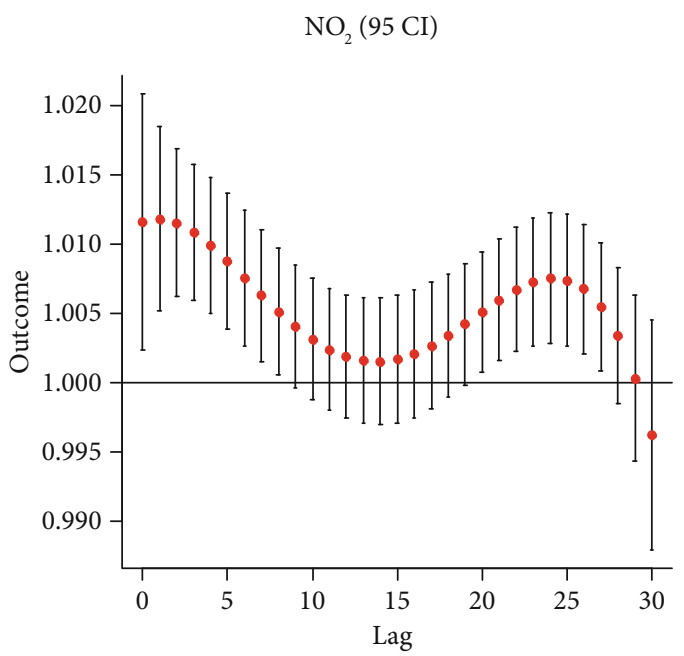

(a)

(b)
Cumulative association with a 10-unit increase in $\mathrm{PM}_{2.5}$

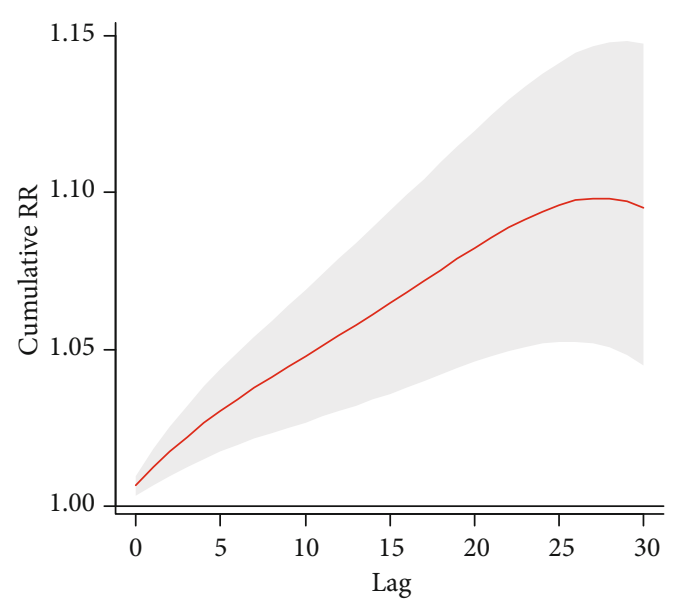

Cumulative association with a 10-unit increase in $\mathrm{PM}_{10}$

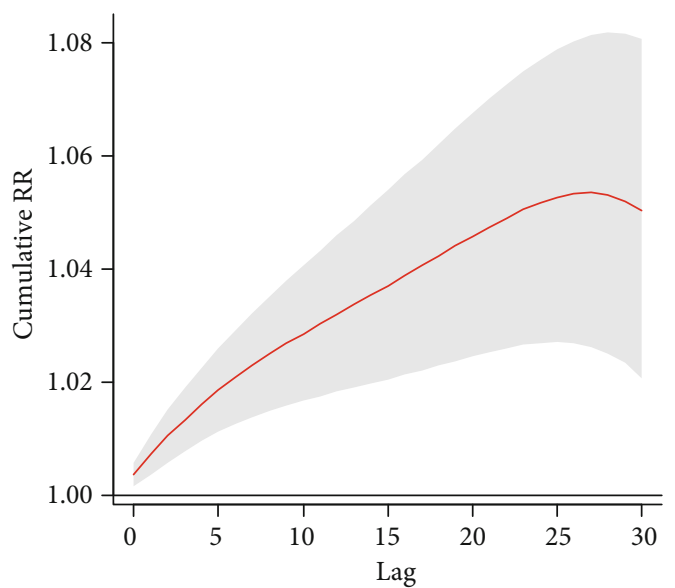

Cumulative association with a 10-unit increase in $\mathrm{NO}_{2}$

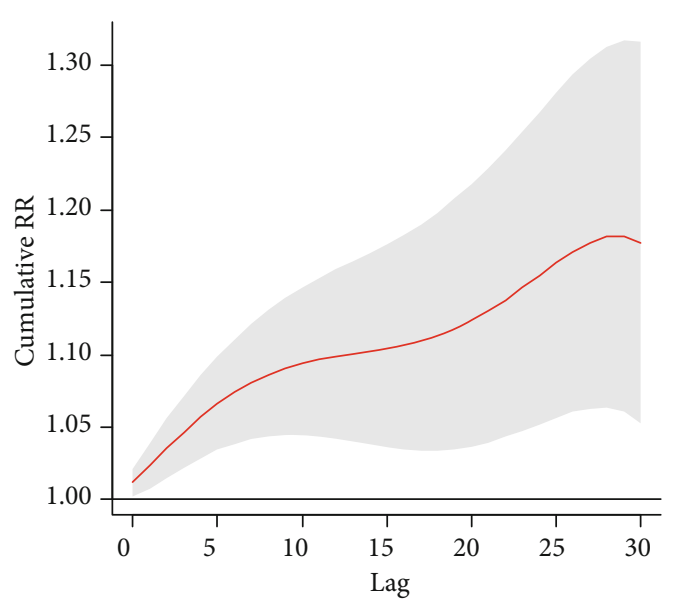

(c)

Figure 4: Continued. 
$\mathrm{SO}_{2}(95 \mathrm{CI})$

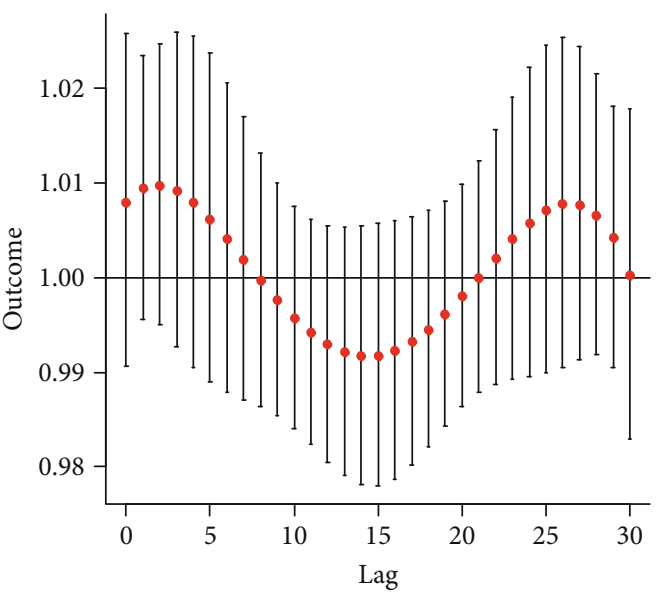

$\mathrm{CO}(95 \mathrm{CI})$

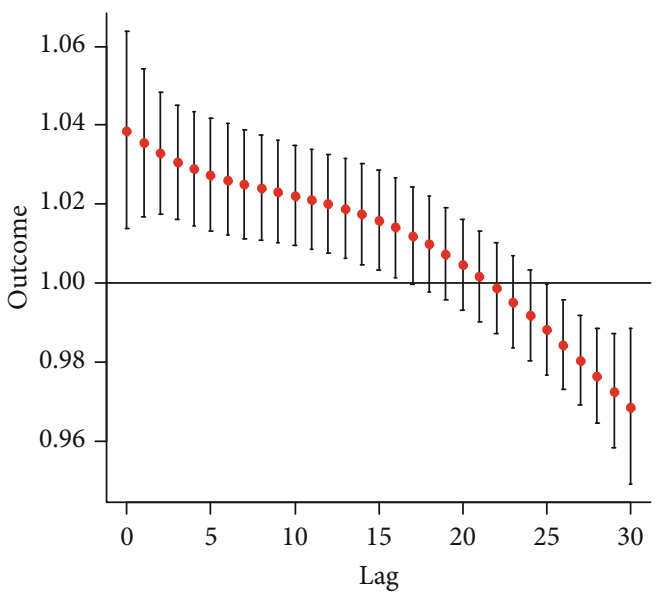

(e)

(d)
Cumulative association with a 10 -unit increase in $\mathrm{SO}_{2}$

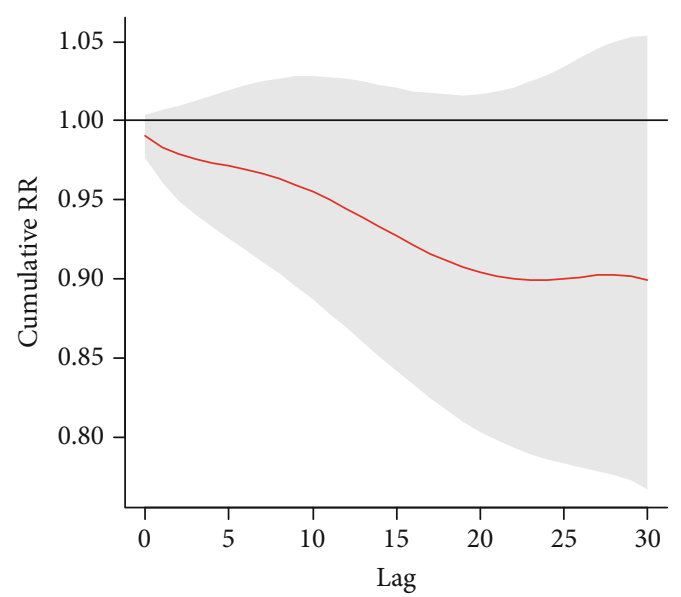

Cumulative association with a 1-unit increase in CO

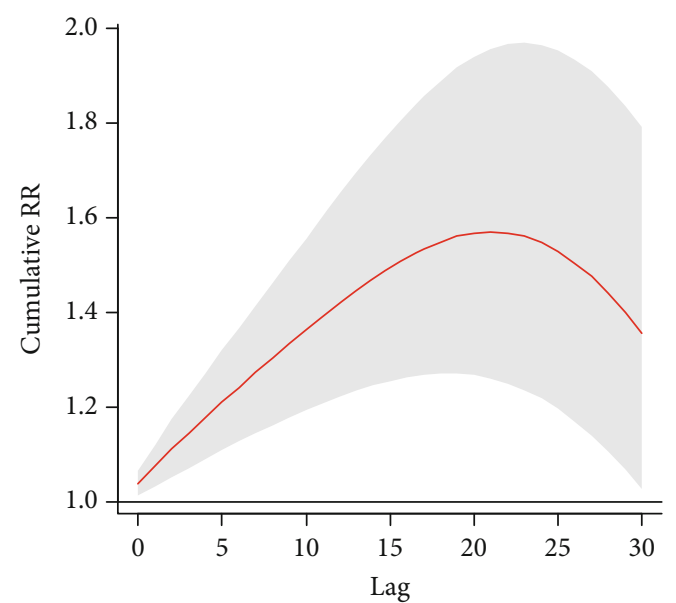

Cumulative association with a 10 -unit increase in $\mathrm{O}_{3}$

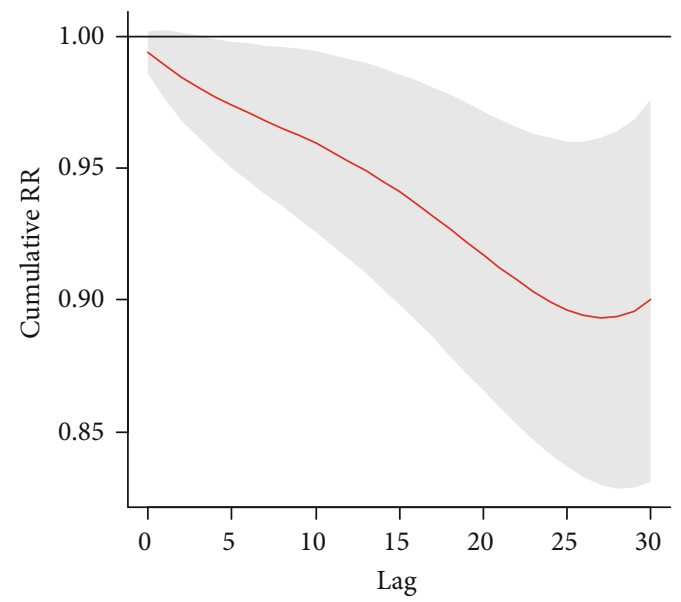

(f)

FIGURE 4: Hysteresis and cumulative effect of air pollutants on the incidence of diabetes in single-pollutant model ((a) $\mathrm{PM}_{2.5}$, (b) $\mathrm{PM}_{10}$, (c) $\mathrm{NO}_{2}$, (d) $\mathrm{SO}_{2}$, (e) $\mathrm{CO}$, and (f) $\mathrm{O}_{3}$ ). 

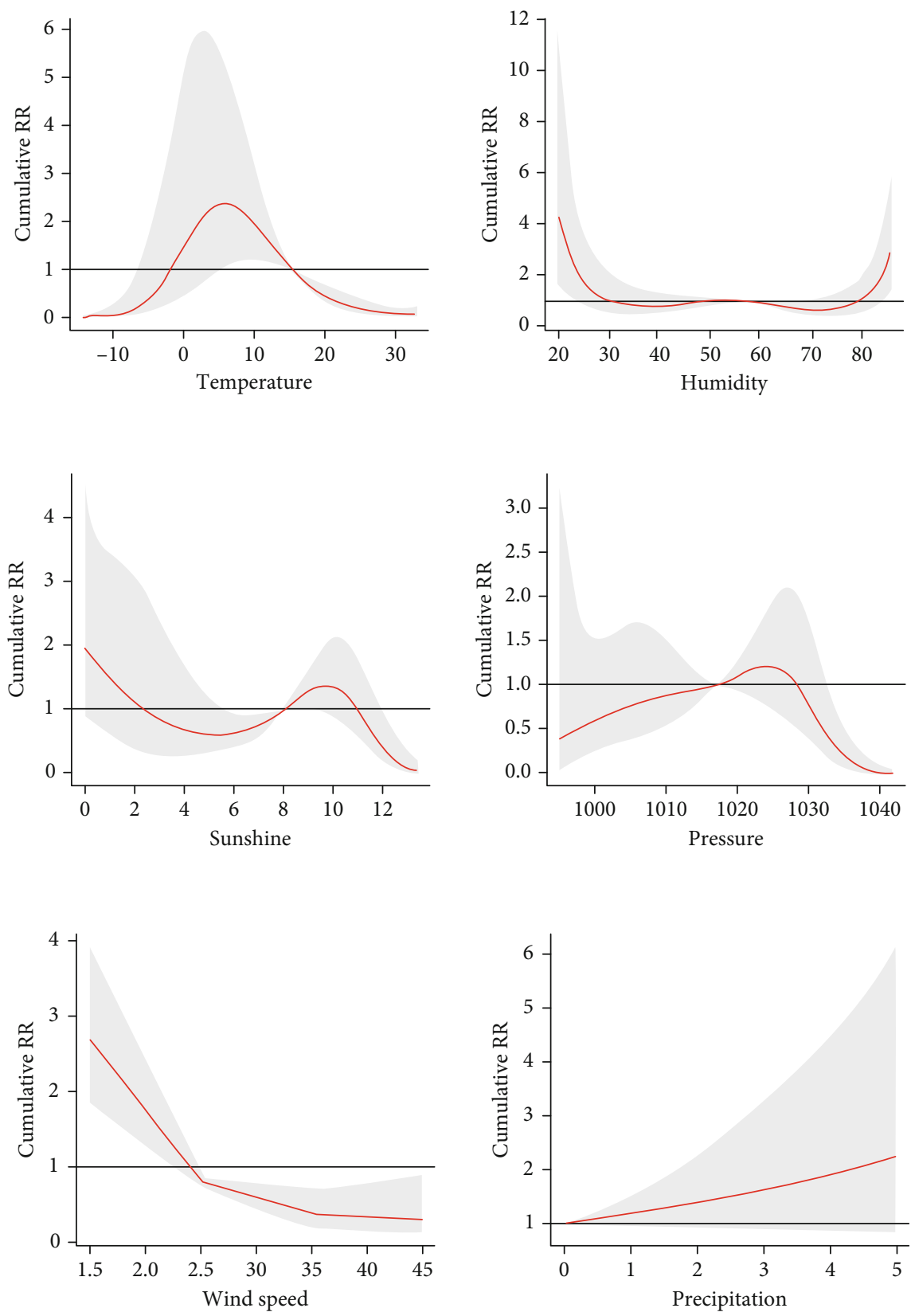

Figure 5: Cumulative effect curve of different meteorological factors on the incidence of diabetes.

of diabetes increased when the pressure was low, especially on the day. After the first five days, the effect was weakened but lasted for about 30 days.

(iv) Precipitation: the risk of diabetes slightly increased when the precipitation reached a certain level. When precipitation further increased to $60 \mathrm{~mm}$ or more, it was negatively correlated with the risk of diabetes.

(v) Wind speed: wind speed ranged from $1.8 \mathrm{~m} / \mathrm{s}$ to $3.0 \mathrm{~m} / \mathrm{s}$. A decrease in wind speed increased diabetes incidence, and the influence was more obvious within five days.

Table 5 summarizes the RR of diabetes in single and double-pollutant models for $10 \mu \mathrm{g} / \mathrm{m}^{3}\left(1 \mathrm{mg} / \mathrm{m}^{3}\right)$ or an inter- quartile range increase in air pollutant concentration. In the single-pollutant model, an increase in $\mathrm{PM}_{2.5}, \mathrm{PM}_{10}$, or $\mathrm{NO}_{2}$ concentrations by $10 \mu \mathrm{g} / \mathrm{m}^{3}$ was associated with an increase in the risk of diabetes by $2.6 \%, 1.9 \%$, and $5.1 \%$, respectively. When the concentration of CO increased by $1 \mathrm{mg} / \mathrm{m}^{3}$, the risk of diabetes increased by $15.6 \%$. The interquartile range increase in the concentrations of $\mathrm{PM}_{2.5}, \mathrm{PM}_{10}, \mathrm{NO}_{2}$, and $\mathrm{CO}$ contributed to an increased risk of diabetes by $14.4 \%$, $15.7 \%, 17.1 \%$, and $15.6 \%$, respectively. The estimator of effect for both $\mathrm{PM}_{10}$ and $\mathrm{PM}_{2.5}$ was relatively robust in the dualpollutant model. There was no statistical association between $\mathrm{SO}_{2}$ and $\mathrm{O}_{3}$ and the risk of diabetes in both the singlepollutant and the dual-pollutant models.

Based on the results of the single-factor model and experience from previous research, we selected relevant factors 

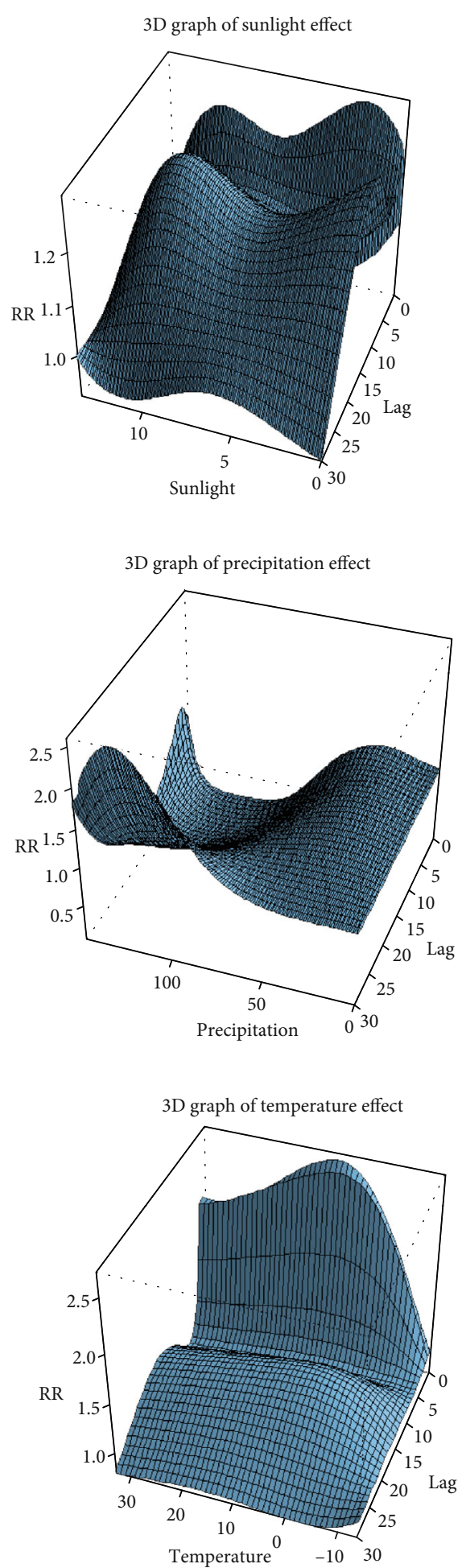

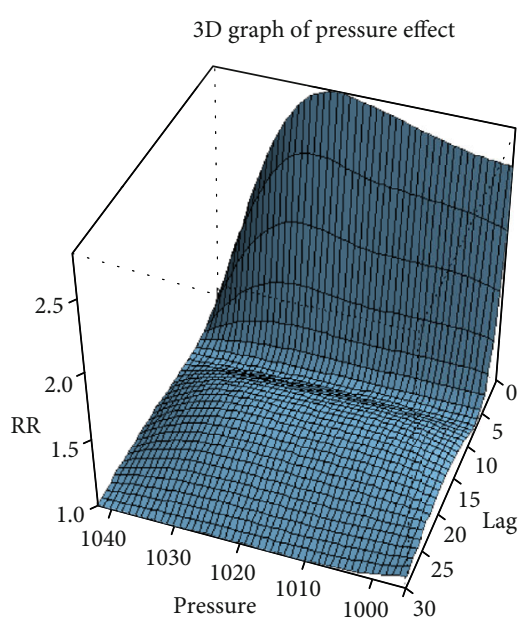

3D graph of humidity effect

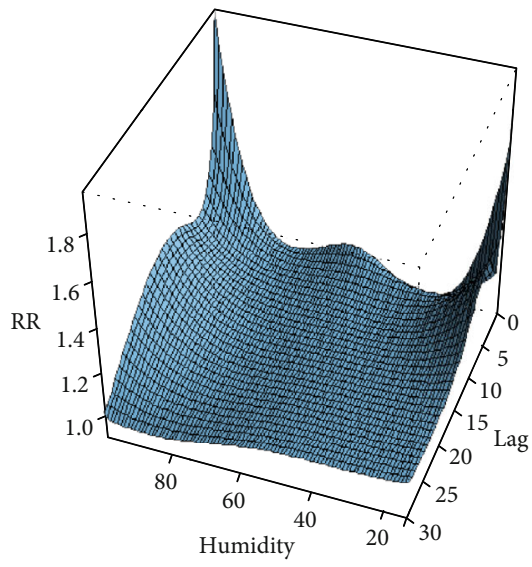

3D graph of wind effect

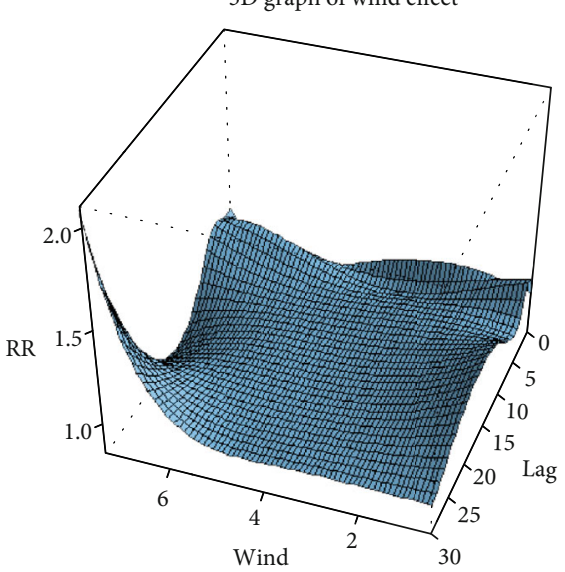

FIgURE 6: Three-dimensional image of the association between meteorological factors and the incidence of diabetes.

into the final multivariate model. The correlation between $\mathrm{PM}_{2.5}$ and $\mathrm{PM}_{10}$ was strong, with a correlation coefficient of 0.897 . We considered there was collinearity between the two pollutants, and therefore, these parameters could not be included in the same final model. Similarly, the correlation coefficient of temperature and atmospheric pressure was -0.886 . To avoid the influence of collinearity, atmospheric pressure was excluded from the final model. The correlation coefficients of the relation between $\mathrm{SO}_{2}$ and $\mathrm{NO}_{2}$ or $\mathrm{CO}$ were $>0.7$, and since $\mathrm{SO}_{2}$ had no apparent correlation with diabetes, we excluded it. Finally, $\mathrm{PM}_{2.5}, \mathrm{NO}_{2}$, and $\mathrm{CO}$ were included in the multivariate model. The diffusion of air pollutants was usually affected by meteorological factors. Therefore, we added temperature, humidity, and duration of 

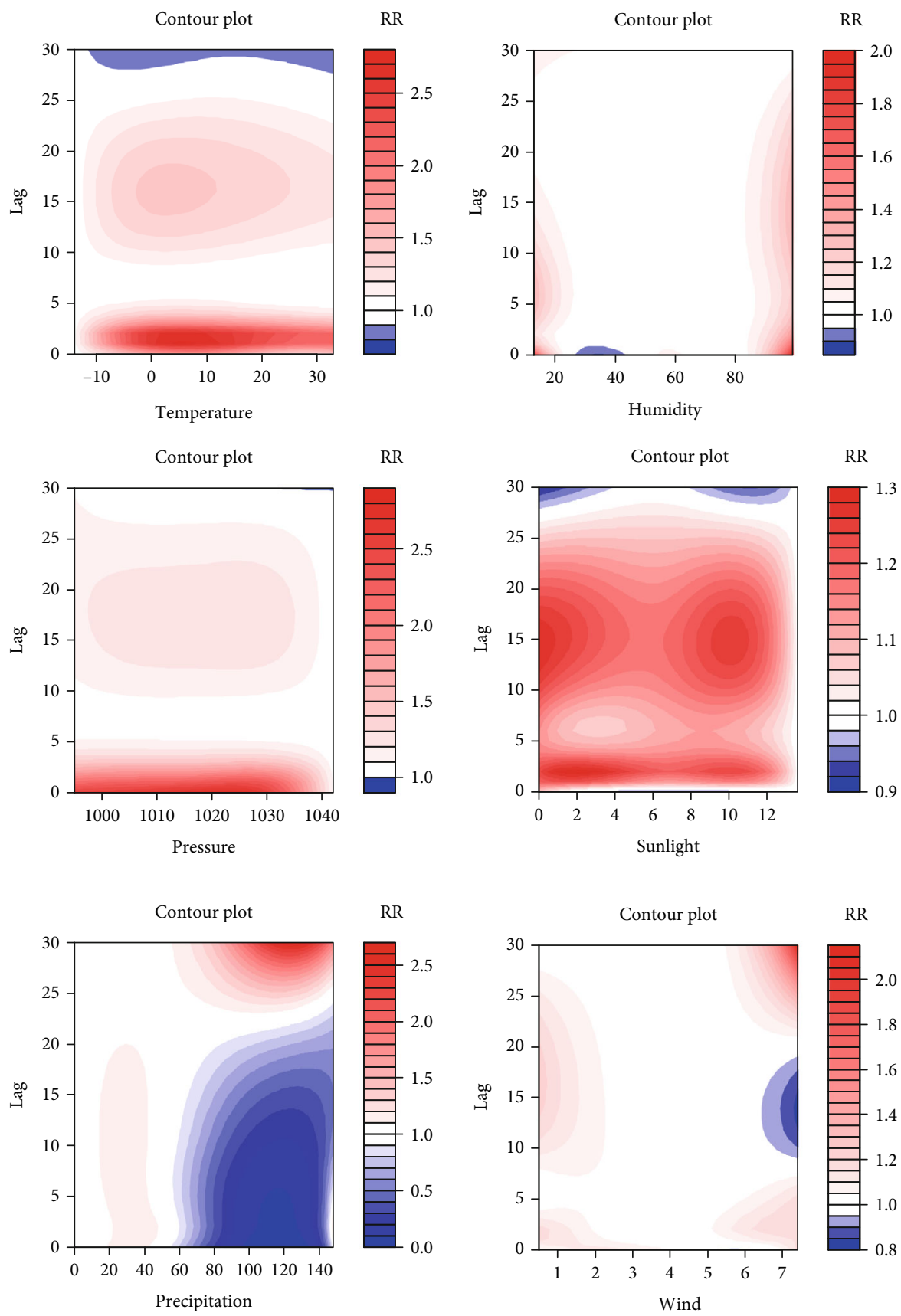

Figure 7: Contour plot of the relationship between meteorological factors and diabetes incidence.

sunshine to the final model as covariates to correct for these confounding factors.

Separate and cumulative effect curves are shown in Figure 8. $\mathrm{PM}_{2.5}$ showed a positive correlation with the incidence of diabetes after eight days, and the adverse effect continued for more than 30 days. The cumulative RR of 30 days was 1.092 (95\% CI: 1.021-1.168). In the separate effect curve, there was no significant correlation between $\mathrm{NO}_{2}$ and the risk of diabetes in the first 11 days, while $\mathrm{NO}_{2}$ was the protective factor for diabetes on the 11th-17th day. After that, $\mathrm{NO}_{2}$ became a risk factor of diabetes between the 23rd and 29th days. The correlation was not evident, and the cumulative effect curve showed no statistically significant correlation between $\mathrm{NO}_{2}$ and diabetes risk (RR: 1.053; 95\% CI: 0.8891.247). Overall, in the final model adjusted for $\mathrm{PM}_{2.5}, \mathrm{NO}_{2}$ was not significantly associated with the onset of diabetes. Finally, combining the separate effect curves and cumulative effect curves, the relationship between $\mathrm{CO}$ and diabetes incidence was not statistically significant in the final model (RR: 0.851; 95\% CI: 0.574-1.261).

The modification effects of age, gender, and BMI on the relationship between air pollution and diabetes incidence were explored by grouping the study population based on these parameters (Table 6). We found no relationship between $\mathrm{NO}_{2}$ and $\mathrm{CO}$ and diabetes in all the groups. For every $10 \mu \mathrm{g} / \mathrm{m}^{3}$ increase in $\mathrm{PM}_{2.5}$, the relative RR of diabetes 
TABLE 5: Fitting results of single and double air pollutant model.

\begin{tabular}{|c|c|c|}
\hline \multirow[b]{2}{*}{ Model } & \multicolumn{2}{|c|}{ Risk ratio $(95 \% \mathrm{CI})$} \\
\hline & $\begin{array}{l}\text { Increase } 10 \mu \mathrm{g} / \mathrm{m}^{3} \\
\text { or } 1 \mathrm{mg} / \mathrm{m}^{3}\end{array}$ & $\begin{array}{c}\text { Increase the } \\
\text { interquartile range }\end{array}$ \\
\hline \multicolumn{3}{|l|}{$P M_{2.5}$} \\
\hline $\mathrm{PM}_{2.5}$ & $1.026(1.011-1.040)^{*}$ & $1.144(1.062-1.233)^{*}$ \\
\hline $\mathrm{PM}_{2.5}+\mathrm{PM}_{10}$ & $0.994(0.972-1.017)$ & $0.971(0.862-1.093)$ \\
\hline $\mathrm{PM}_{2.5}+\mathrm{NO}_{2}$ & $1.020(1.001-1.038)^{*}$ & $1.109(1.007-1.222)^{*}$ \\
\hline $\mathrm{PM}_{2.5}+\mathrm{SO}_{2}$ & $1.033(1.016-1.050)^{*}$ & $1.189(1.090-1.297)^{*}$ \\
\hline $\mathrm{PM}_{2.5}+\mathrm{CO}$ & $1.022(1.005-1.039)^{*}$ & $1.121(1.026-1.225)^{*}$ \\
\hline $\mathrm{PM}_{2.5}+\mathrm{O}_{3}$ & $1.026(1.012-1.041)^{*}$ & $1.147(1.064-1.236)^{*}$ \\
\hline \multicolumn{3}{|l|}{$P M_{10}$} \\
\hline $\mathrm{PM}_{10}$ & $1.019(1.012-1.026)^{*}$ & $1.157(1.093-1.225)^{*}$ \\
\hline $\mathrm{PM}_{10}+\mathrm{PM}_{2.5}$ & $1.021(1.010-1.033)^{*}$ & $1.178(1.077-1.289)^{*}$ \\
\hline $\mathrm{PM}_{10}+\mathrm{NO}_{2}$ & $1.017(1.009-1.025)^{*}$ & $1.142(1.072-1.216)^{*}$ \\
\hline $\mathrm{PM}_{10}+\mathrm{SO}_{2}$ & $1.021(1.013-1.029)^{*}$ & $1.179(1.109-1.252)^{*}$ \\
\hline $\mathrm{PM}_{10}+\mathrm{CO}$ & $1.018(1.010-1.026)^{*}$ & $1.146(1.077-1.218)^{*}$ \\
\hline $\mathrm{PM}_{10}+\mathrm{O}_{3}$ & $1.019(1.012-1.027)^{*}$ & $1.158(1.094-1.226)^{*}$ \\
\hline \multicolumn{3}{|l|}{$\mathrm{NO}_{2}$} \\
\hline $\mathrm{NO}_{2}$ & $1.051(1.019-1.083)^{*}$ & $1.171(1.063-1.290)^{*}$ \\
\hline $\mathrm{NO}_{2}+\mathrm{PM}_{2.5}$ & $1.023(0.984-1.063)$ & $1.075(0.949-1.217)$ \\
\hline $\mathrm{NO}_{2}+\mathrm{PM}_{10}$ & $1.022(0.989-1.057)$ & $1.073(0.966-1.193)$ \\
\hline $\mathrm{NO}_{2}+\mathrm{SO}_{2}$ & $1.078(1.037-1.120)^{*}$ & $1.270(1.122-1.438)^{*}$ \\
\hline $\mathrm{NO}_{2}+\mathrm{O}_{3}$ & $1.051(1.019-1.083)^{*}$ & $1.171(1.062-1.291)^{*}$ \\
\hline $\mathrm{NO}_{2}+\mathrm{CO}$ & $1.032(0.995-1.071)$ & $1.107(0.984-1.244)$ \\
\hline \multicolumn{3}{|l|}{$\mathrm{CO}$} \\
\hline $\mathrm{CO}$ & $1.156(1.058-1.264)^{*}$ & - \\
\hline $\mathrm{CO}+\mathrm{NO}_{2}$ & $1.097(0.984-1.224)$ & - \\
\hline $\mathrm{CO}+\mathrm{PM}_{2.5}$ & $1.065(0.958-1.185)$ & - \\
\hline $\mathrm{CO}+\mathrm{PM}_{10}$ & $1.066(0.968-1.174)$ & - \\
\hline $\mathrm{CO}+\mathrm{SO}_{2}$ & $1.195(1.074-1.329)^{*}$ & - \\
\hline $\mathrm{CO}+\mathrm{O}_{3}$ & $1.160(1.061-1.269)^{*}$ & - \\
\hline
\end{tabular}

was 1.163 (95\% CI: 1.032-1.311) in females, while there was no statistical correlation in men. In the different age groups, $\mathrm{PM}_{2.5}$ was more strongly associated with diabetes in older people ( $\geq 75$ years) than those aged under 75 years. For every $10 \mu \mathrm{g} / \mathrm{m}^{3}$ increase in $\mathrm{PM}_{2.5}$, the $\mathrm{RR}$ of diabetes incidence increased by 1.140 (95\% CI: 1.032-1.259). Exposure to $\mathrm{PM}_{2.5}$ was positively correlated with diabetes incidence in healthy weight and obese people. When the concentration of $\mathrm{PM}_{2.5}$ increased by $10 \mu \mathrm{g} / \mathrm{m}^{3}$, the relative $\mathrm{RR}$ of obese and healthy-weight people was 1.135 (95\% CI: 1.007-1.279) and 1.221 (95\% CI: 1.042-1.431), respectively.

\section{Discussion}

Our study found that, in the population aged $\geq 60$ years old from the Binhai New District in 2014-2017, there was a positive correlation between exposure to not only $\mathrm{PM}_{2.5}$ but also $\mathrm{PM}_{10}$ and diabetes incidence after multiple adjustments and between $\mathrm{NO}_{2}, \mathrm{CO}$, and diabetes incidence in a singlepollutant model. Further stratification analysis found that the relationship between exposure to $\mathrm{PM}_{2.5}$ and diabetes was more robust in female subjects, subjects aged $\geq 75$ years old, and obese people. In addition, meteorological factors were also found to be associated with the development of diabetes, and this association was nonlinear.

4.1. $P M_{2.5}$. In the population aged 60 and over in the Tianjin Binhai New District, we found that $\mathrm{PM}_{2.5}$ was positively correlated with the incidence of diabetes in both the singlepollutant and the dual-pollutant models, which was consistent with a previous study conducted in Hong Kong, China [33]. In our multivariate model, $\mathrm{PM}_{2.5}$ increases by each interquartile range $\left(53 \mathrm{~g} / \mathrm{m}^{3}\right)$ resulting in a relative $\mathrm{RR}$ of diabetes of 1.59 (95\% CI: 1.11-2.27), which represented a $59 \%$ increase in the risk of diabetes. The Hong Kong cohort study used logistic regression and time-varying Cox regression models to assess the prevalence and risk of diabetes associated with $\mathrm{PM}_{2.5}$ among the elderly and found that after adjusting for potential individual and neighborhood confounders, the hazard ratio (HR) for diabetes was $1.15(95 \%$ CI: $1.05-1.25)$ per interquartile range $\left(3.2 \mu \mathrm{g} / \mathrm{m}^{3}\right)$ increase in $\mathrm{PM}_{2.5}$. Although this finding suggests a relationship between long-term exposures to $\mathrm{PM}_{2.5}$ and our study investigated short-term effects, the results in different regions of China were similar. Compared with our study, their results showed a weaker correlation between $\mathrm{PM}_{2.5}$ and diabetes. We consider that this might be due to differences in statistical methods and adjustment factors. Furthermore, the $\mathrm{PM}_{2.5}$ levels in our study were significantly higher than those measured in the Hong Kong study.

Another cohort study followed US veterans for 8.5 years and showed that there were approximately 32 million diabetic patients due to prolonged exposure to $\mathrm{PM}_{2.5}$ in 2016, accounting for $14 \%$ of global diabetes patients [34]. A study based on the SALIA cohort in Germany found that trafficrelated air pollution, including $\mathrm{NO}_{2}$ and $\mathrm{PM}_{2.5}$, was associated with an increased risk of type 2 diabetes in women aged 54-55 years [35]. Similarly, a cohort study in Canada with a 30-year follow-up of women between the ages 40 and 59 described the relationship between $\mathrm{PM}_{2.5}$ and diabetes using Poisson regression models and found that for every $10 \mu \mathrm{g} / \mathrm{m}^{3}$ increase in $\mathrm{PM}_{2.5}$, the risk of type 2 diabetes increased by $28 \%$ [36]. A meta-analysis, including 13 studies conducted in Europe and North America, reached the same conclusion. In this study, a combined relative RR of type 2 diabetes was 1.10 (95\% CI: $1.02-1.18$ ) for every $10 \mu \mathrm{g} / \mathrm{m}^{3}$ increase in PM 2.5 [37]. A large cohort study in Rome, Italy, used logistic and Cox regression models to assess the relationship between long-term exposure to $\mathrm{PM}$, nitrogen oxides $\left(\mathrm{NO}_{\mathrm{x}}\right)$, ozone $\left(\mathrm{O}_{3}\right)$, and the incidence of type 2 diabetes at individual levels. For every $20 \mu \mathrm{g} / \mathrm{m}^{3}$ increase in $\mathrm{NO}_{\mathrm{x}}$ and $10 \mu \mathrm{g} / \mathrm{m}^{3}$ increase in $\mathrm{O}_{3}$, the hazard ratio (HR) for diabetes was found to be 1.01 (95\% CI:1.00-1.02) and 1.02 (95\% CI:1.00-1.03), respectively. However, no clear correlation was found between $\mathrm{PM}_{2.5}$, $\mathrm{PM}_{10}$, and diabetes incidence [38]. This discrepancy might be explained by substantial differences between the levels of air pollutants in Italy and China. The average concentrations 
Association with a 10-unit increase in $\mathrm{PM}_{2.5}$

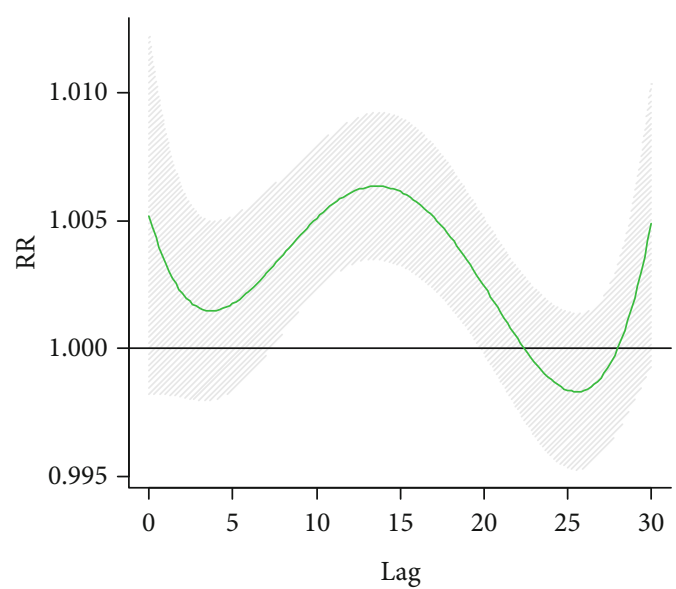

Association with a 10 -unit increase in $\mathrm{NO}_{2}$

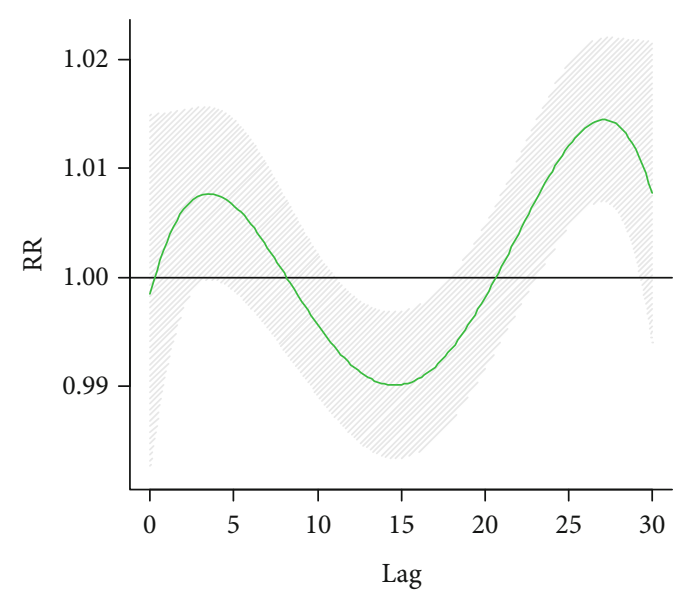

Association with a 1-unit increase in $\mathrm{CO}$

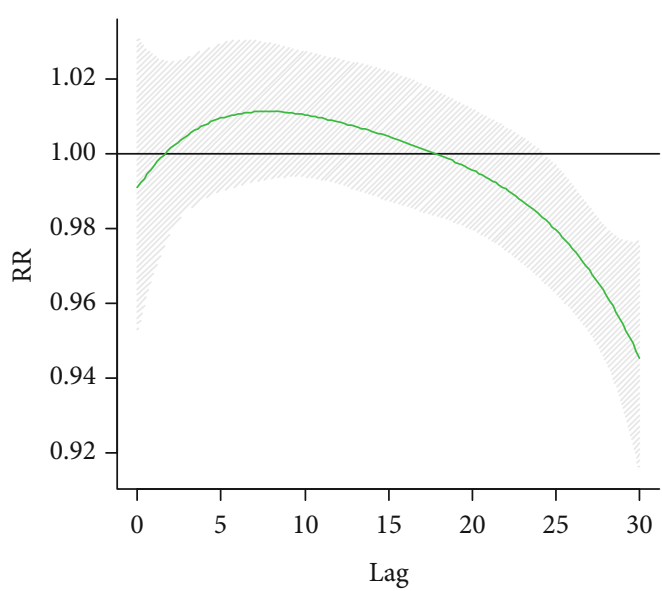

Cumulative association with a 10 -unit increase in $\mathrm{PM}_{2.5}$

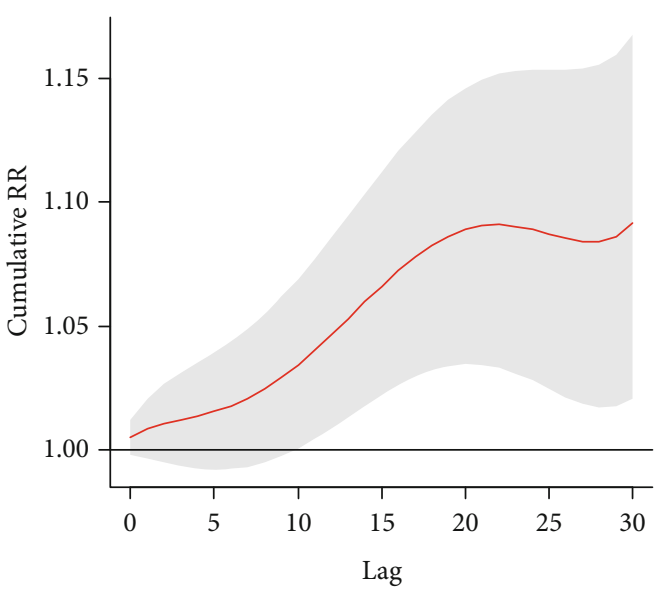

Cumulative association with a 10 -unit increase in $\mathrm{NO}_{2}$

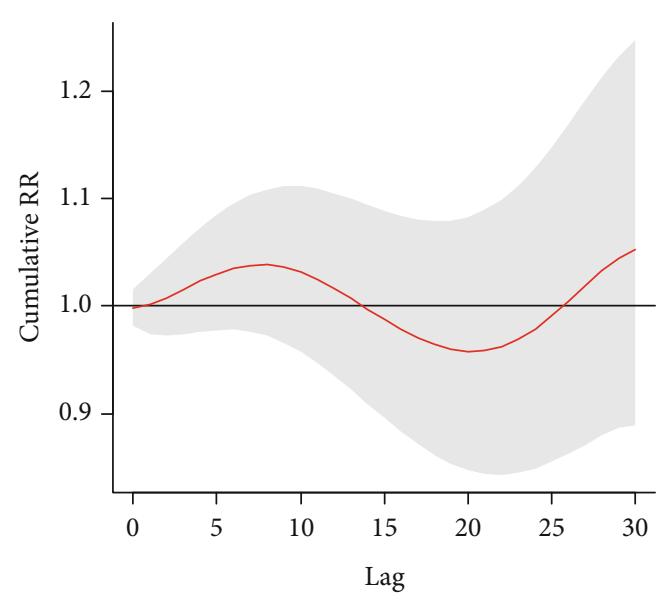

Cumulative association with a 1-unit increase in $\mathrm{CO}$

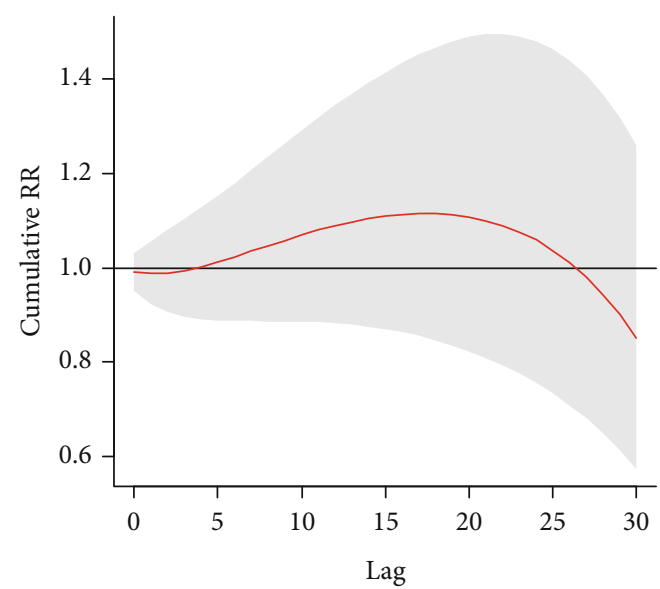

FIGURE 8: Hysteresis and cumulative effect of air pollutants on diabetes in multivariate model.

of PM in our study area were about three times than that of those measured in Italy. Additionally, Italy is a developed country in Europe, and there might be economic and ethnic differences with China. Finally, our study was aimed at the elderly population, and the Italy study was conducted in peo- ple over the age of 35 ; therefore, the tolerance to air pollution of the population might be different.

4.2. $P M_{10}$ and $\mathrm{NO}_{2}$. We found that exposure to $\mathrm{PM}_{10}$ and $\mathrm{NO}_{2}$ was positively correlated with the incidence of diabetes, 
TABLE 6: Results of subgroup analysis based on sex, age, and BMI.

\begin{tabular}{|c|c|c|c|c|}
\hline & $\begin{array}{l}\text { T2DM } \\
\text { Number }\end{array}$ & $\mathrm{PM}_{2.5}$ & $\begin{array}{c}\mathrm{NO}_{2} \\
\operatorname{RR}(95 \% \mathrm{CI})\end{array}$ & $\mathrm{CO}$ \\
\hline \multicolumn{5}{|l|}{ Sex } \\
\hline Male & 3405 & $1.070(0.988-1.157)$ & $1.006(0.860-1.177)$ & $0.943(0.603-1.473)$ \\
\hline Female & 4180 & $1.163(1.032-1.311)^{*}$ & $1.044(0.846-1.289)$ & $0.837(0.508-1.380)$ \\
\hline \multicolumn{5}{|l|}{ Age } \\
\hline$<75$ & 6214 & $1.109(1.031-1.193)^{*}$ & $1.071(0.894-1.283)$ & $0.805(0.528-1.228)$ \\
\hline$\geq 75$ & 1371 & $1.140(1.032-1.259)^{*}$ & $0.803(0.633-1.018)$ & $1.167(0.626-2.175)$ \\
\hline \multicolumn{5}{|l|}{$B M I$} \\
\hline Low weight $(<18.5)$ & 51 & $0.960(0.542-1.700)$ & $0.477(0.163-1.402)$ & $2.691(0.129-55.997)$ \\
\hline Normal (18.5-23.99) & 2138 & $1.221(1.042-1.431)^{*}$ & $0.829(0.564-1.219)$ & $0.593(0.242-1.451)$ \\
\hline Overweight (24-27.99) & 3715 & $1.074(0.986-1.169)$ & $1.062(0.866-1.302)$ & $0.810(0.481-1.364)$ \\
\hline Obesity $(\geq 28)$ & 1698 & $1.135(1.007-1.279)^{*}$ & $0.811(0.614-1.070)$ & $1.270(0.625-2.578)$ \\
\hline Total & 7585 & $1.092(1.021-1.168)^{*}$ & $1.053(0.889-1.247)$ & $0.851(0.574-1.261)$ \\
\hline
\end{tabular}

similar to the results of previous studies [39, 40]. A population-based study in Germany conducted a random sampling of 45 to 72 -year-old residents in highly urbanized areas and followed them for 5.1 years. The study concluded that $\mathrm{PM}_{10}$ was associated with an increased risk of diabetes, and the RR obtained with Poisson regression adjusting for sex, age, BMI, lifestyle factors, area and individual-level socioeconomic status, and city was 1.05 (95\% CI: 1.00-1.10) [42]. A meta-analysis combined the results of ten cohort studies and concluded that every $10 \mu \mathrm{g} / \mathrm{m}^{3}$ increase in $\mathrm{PM}_{10}$ and $\mathrm{NO}_{2}$ was connected with an increased risk of diabetes by $10 \%$ (95\% CI: $22 \%-47 \%)$ and $11 \%$ (95\% CI: $7 \%-16 \%)$, respectively [41]. However, a study from Tianjin, China, showed different results. It was found that among people aged between 45 and 64 years, the risk of diabetes increased by $1.16 \%$ for every $10 \mu \mathrm{g} / \mathrm{m}^{3}$ increase of $\mathrm{NO}_{2}$, while $\mathrm{PM}_{10}$ and diabetes were not significantly correlated [42]. However, our results showed that in the single-pollutant model, both $\mathrm{PM}_{10}$ and $\mathrm{NO}_{2}$ were positively correlated with the onset of diabetes, and the correlation between $\mathrm{NO}_{2}$ and diabetes was stronger. The number of diabetic cases increased by $5.1 \%$ for every $10 \mu \mathrm{g} / \mathrm{m}^{3}$ increase in $\mathrm{NO}_{2}$. Both studies performed short-term health effects on diabetes using time-series analysis and were conducted in Tianjin. However, our study was aimed at the Binhai New District, and the scope of that study was the urban area of Tianjin. Furthermore, the research periods were different. Comparing the average levels of air pollution, we found that the air pollution level in the Binhai New District from 2014 to 2017 was higher than that in the urban area of Tianjin in 2008-2011. Additionally, the study population was older, leading to a more vulnerable population being exposed to higher levels of air pollution, likely causing more significant adverse effects.

4.3. $\mathrm{O}_{3}, \mathrm{CO}$, and $\mathrm{SO}_{2}$. Our results suggested that there was no statistically significant association between $\mathrm{O}_{3}$ and diabetes in the elderly population of the Binhai New District. Similarly, a six-year study conducted among MexicanAmericans explored the adverse effects of air pollution on insulin resistance resulting in a similar conclusion [43]. The production of ozone requires the action of ultraviolet rays. When there is a high concentration of environmental PM, the ultraviolet rays of solar radiation will be scattered to some extent [44]. $\mathrm{O}_{3}$ was negatively correlated with the concentration of $\mathrm{PM}_{2.5}$ and $\mathrm{PM}_{10}$, indicating that $\mathrm{O}_{3}$ may cause the elution period of $\mathrm{PM}_{2.5}$ and $\mathrm{PM}_{10}$, thus failing to reflect the correlation between $\mathrm{O}_{3}$ and diabetes. However, in 45,231 African-American women from 56 regions of the United States, air pollution was distributed to individual levels through EPA Models-3/Community Multiscale Air Quality (CMAQ) predictions fused with ground measurements. Cox proportional hazards models were used to analyze this relationship. The HR per interquartile range increase of $\mathrm{O}_{3}$ was 1.18 (95\% CI: 1.04-1.34) for the incidence of diabetes in adjusted models [45]. The discrepancy with our data may be due to different statistical methods used. We explored at the group level, while the American study was specific to individuals. Additionally, that study only involved women, while we conducted our study on the whole elderly population, which may have resulted in differences in performance between different populations exposed to $\mathrm{O}_{3}$. In addition to $\mathrm{O}_{3}$, we did not find a correlation between $\mathrm{SO}_{2}$ and $\mathrm{CO}$ and the incidence of diabetes. A large cohort study with a longer follow-up is required to confirm these data.

4.4. Possible Mechanism behind the Effect of Air Pollution on Diabetes Incidence. Research on the mechanisms behind the relationship between air pollutants and the increased incidence of diabetes mainly focused on PM. In both animal and human experiments, the levels of interleukin-6 (IL-6) and tumor necrosis factor- $\alpha$ (TNF- $\alpha$ ) were elevated after exposure to PM [46-48]. Inflammatory markers are significantly associated with diabetes, and elevated levels of IL-6 can increase the risk of diabetes by $31 \%$ [49], indicating that air pollution can affect the development of diabetes through systemic inflammatory responses. Besides, animal experiments have shown that exposure to $\mathrm{PM}_{2.5}$ is associated with a decrease of insulin signaling in the liver, which inhibits 
the translocation of glucose transporter 4 (GLUT4), providing evidence that air pollution enhances insulin resistance in the liver $[46,50]$. Moreover, exposure to $\mathrm{PM}_{2.5}$ also induces lipid deposition in the liver and reduces gluconeogenesis, inhibiting insulin receptor substrate 1- (IRS-1-) mediated signaling in the liver, which is associated with insulin resistance and abnormal glucose homeostasis [51].

\subsection{Meteorological Factors}

4.5.1. Temperature. Our study found that high temperatures promoted diabetes, and a previous study using 14-year longitudinal data from the United States reached a similar conclusion. Using meta-regression, they determined the effect of mean annual temperature on diabetes incidence between 1996 and 2009 for each US state. Compared to cold years, the incidence of diabetes was higher in warm years, and the age-adjusted diabetes incidence increased by 0.314 per $1^{\circ} \mathrm{C}$ [22]. However, no previous research was conducted in China on the correlation of diabetes incidence and meteorological factors. The activity of brown adipose tissue (BAT) is negatively correlated with outdoor temperature. Increased fatty acid flow to BAT can lead to a compensatory increase in glucose transport to other metabolically active tissues and even weight loss [52-54]. Therefore, insulin sensitivity is improved at lower temperatures, which may explain the adverse effects of elevated temperature on diabetes.

4.5.2. Humidity. We found that extreme moist or dry air was harmful to human health. Research in the Midwest of Africa supports our result, showing that the number of diabetes cases was highest in the wettest months and the hospital admission rate of diabetic patients was also slightly higher during the rainy season [52-54]. This may be related to the decline in body function and poor physiological response abilities in humid conditions. Instead of meteorological factors themselves, humidity also interacts with air pollutants, in turn affecting human health. In a previous study (conducted in Beijing, adjacent to Tianjin) on the relationship between air pollutants and meteorological factors, it was found that there was seasonal variability in the correlation between humidity and air pollution. Lower humidity was likely causing air pollution in spring and higher humidity likely contributed to air pollution in the other seasons, partly explaining why extreme humidity affects human health adversely [55].

4.5.3. Sunshine. In our study, a reduction of sunshine duration increased the risk of diabetes. The only other study that examined the association between sunshine and diabetes incidence was a prospective cohort study of women aged 25 to 64 years in southern Sweden. The average follow-up time was 11 years, and data were analyzed by logistic regression analysis. It was found that, compared to women without activity habits, women with sun exposure habits had a lower risk of developing type 2 diabetes [23]. Solar radiation is the primary source of vitamin D. Vitamin D appears to play a role in pancreatic diseases, including type 1 and type 2 diabetes [56]. It can affect the function of beta cells and influence insulin sensitivity. Furthermore, it can reduce systemic inflammatory responses by controlling blood pressure, reducing peripheral vascular resistance, or acting as an immunomodulator to prevent excessive production of inflammatory cytokines [57-59]. Therefore, sunshine may prevent the development of type 2 diabetes by increasing serum 25-(OH)2-D3 levels.

4.5.4. Atmospheric Pressure. We found that low air pressure was associated with a higher diabetes incidence. No previous research investigated the impact of atmospheric pressure on diabetes incidence. However, a multicenter study showed that increased atmospheric pressure was beneficial to reduce mortality [60]. In addition, it was previously found that the concentration of air pollutants is affected by the domestic trans-boundary impacts (TBI), which contributed to $27 \%$ of the total $\mathrm{PM}_{2.5}$ in China [61]. At lower atmospheric pressure, between $900 \mathrm{hPa}$ and $850 \mathrm{hPa}$, wind can more easily transport air pollutants between different regions, aggravating the adverse effects of air pollution. What is more, air pollution is relatively severe when atmospheric pressure is lower, partly affecting the relationship between low air pressure and diabetes.

4.5.5. Precipitation. We found that precipitation might promote diabetes within a specific range, consistent with previous findings from studies conducted in the capital of Cameroon, a Midwestern African country [62]. However, in our study, when the precipitation exceeded the 99th percentile $(60 \mathrm{~mm})$, it was a protective factor within 20 days, and it showed adverse effect on diabetes after 23 days. Given this result, we consider that precipitation was greater than $60 \mathrm{~mm}$ only in 2 out of the 1461 days, and deviations might be caused by these extreme values, as rainstorms could reduce air pollutants on the day of measurement [63]. Therefore, the combined effect makes the number of onset diabetes decline in the short term.

4.5.6. Wind Speed. A study in Beijing showed that the effect of wind speed on air quality differed between seasons. When the wind speed was less than $1 \mathrm{~m} / \mathrm{s}$, the probability of air pollution in autumn and winter was more than $68.06 \%$, while when the wind speed was $2 \mathrm{~m} / \mathrm{s}$ in spring and summer, the probability of pollution reached the maximum [55]. This is in line with our data. We showed that the number of people with diabetes increased when wind speed was under $2 \mathrm{~m} / \mathrm{s}$. We hypothesize this may be related to the slower dissipation of air pollutants at low wind speed.

4.6. Subgroup Analysis. To adjust for possible confounding factors, we conducted a subgroup analysis based on gender, age, and BMI. Analysis by gender showed that there was a more significant association between $\mathrm{PM}_{2.5}$ and diabetes incidence in women (RR: 1.12; 95\% CI: 1.02-1.22). The Hong Kong study mentioned earlier reached the same conclusion [55]. That study involved 66,820 adults aged 65 years or older and stratified analyses by sex. They showed that the associations between $\mathrm{PM}_{2.5}$ exposure and prevalence and incidence of type 2 diabetes mellitus were only statistically significant in women (RR: 1.07; 95\% CI: 1.01-1.13). Additionally, a meta-analysis combining the results of four studies in Europe 
or the United States found that women tended to be affected more than men, with a relative risk of 1.14 (95\% CI: 1.031.26) in women and 1.04 in men (95\% CI: 0.93-1.17) [37]. It seems the response intensity of men and women to air pollution is different, but the specific relationship and the mechanism behind it remain unclear. This may be due to gender-related biological differences, such as hormones and body size, diet, and activity patterns. Women's airway diameters are different from those in men, which leads to an easier deposition of $\mathrm{PM}_{2.5}$ in female airways [64]. In the subgroup analysis, we also found that the population aged $\geq 75$ years (RR: 1.14; 95\% CI: 1.03-1.31) was more susceptible to $\mathrm{PM}_{2.5}$ than the younger population (RR: 1.16; 95\% CI: 1.03-1.31). A case-crossover study conducted in Anshan, China, explored the relationship between air pollution and daily mortality and also found that people aged $\geq 75$ years were more susceptible to air pollutants, supporting our conclusion [65]. This may be attributed to the gradual decline of physiological function, as well as the poorer physical reserves and stress response of older people [66]. The immune system of the elderly is weakened, and aging has been associated with subclinical systemic inflammation. Therefore, older people are prone to systemic inflammation when they are persistently exposed to air pollutants [67]. We found a positive correlation between $\mathrm{PM}_{2.5}$ and diabetes incidence in healthy weight and obese people. A cohort of 28,831 nurses in Denmark found that $\mathrm{PM}_{2.5}$ was most strongly associated with diabetes in obese people, with a hazard risk of 1.25 (95\% CI:1.06-1.47) [68]. Exposure to air pollutants could promote the occurrence and progression of inflammatory reactions, and obesity is associated with higher levels of systemic inflammation, making obese people more susceptible to air pollution $[48,69]$.

4.7. Limitations and Strengths. First of all, diabetes is a chronic disease, and it is challenging to determine the exact day of incidence, so we took the diagnosis date instead. Secondly, due to limitations in the data available and technical constraints, we could not accurately correlate air pollutant concentrations to individuals. Therefore, we could only study patients at the group level. Third, there were many potential confounding factors, such as noise, and their interaction with air pollution has not been widely evaluated. However, the effects of meteorological factors and long-term trends were considered in this study, and subgroup analyses were performed based on age, gender, and BMI, to ensure the results could explain the association between diabetes and air pollution to some extent. Another limitation is that we only obtained data about outdoor air pollutants, while indoor air pollution concentrations, as well as those in some working environments, are much higher than outdoors [70, 71]. Another issue is that air pollutants are complex mixtures. It consists of variable physical properties or chemical compositions, and we could not analyze the single components. However, the single and multivariate models we used are accepted widely, making analysis feasible and comparable.

This is the first study in China into the possible association between air pollutants in the coastal area and the risk of diabetes in the elderly population and fills the gap of knowledge of the impact of Chinese meteorological factors on the risk of diabetes.

\section{Conclusion}

We found a positive correlation between air pollutants, such as $\mathrm{PM}_{2.5}$, and diabetes risk, consistent with previous studies. This finding may have an impact on strategies to reduce diabetes risk. Meteorological factors were also found to play an essential role in the occurrence, development, and dissipation of air pollution and can also directly affect diabetes. However, due to the limitations of this study, more advanced air pollutant estimation techniques and statistical methods are needed to explore in a wider geographical area and a larger population.

\section{Data Availability}

The data are included in the article.

\section{Conflicts of Interest}

The authors declare that they have no competing interests.

\section{Acknowledgments}

This work was supported by the financial support from the National Natural Science Foundation of China (no. 81600643 and no.91746205), the Tianjin Health Industry Key Research Projects (no. 15KG101), the Tianjin Science and Technology Support Project (no. 17JCYBJC27000), and Key Projects of Tianjin Natural Science Foundation (no.18JCZDJC32900), Scientific Research Funding of Tianjin Medical University Chu Hsien-I Memorial Hospital (account number 2016DX01), Science Foundation of Tianjin Medical University (account number 2016KYZQ19), Science and Technology Project of Tianjin Binhai New District Health and Family Planning Commission (account number 2017BWKY031).

\section{Supplementary Materials}

The GAM for meteorological factors was partly same as that for air pollution and is shown in the Supplementary Materials. (Supplementary Materials)

\section{References}

[1] Global Burden of Disease Study 2013 Collaborators, "Global, regional, and national incidence, prevalence, and years lived with disability for 301 acute and chronic diseases and injuries in 188 countries, 1990-2013: a systematic analysis for the Global Burden of Disease Study 2013," The Lancet, vol. 386, no. 9995, pp. 743-800, 2015.

[2] C. D. Mathers and D. Loncar, "Projections of global mortality and burden of disease from 2002 to 2030," PLoS Medicine, vol. 3, no. 11, article e442, 2006.

[3] L. Guariguata, D. R. Whiting, I. Hambleton, J. Beagley, U. Linnenkamp, and J. E. Shaw, "Global estimates of diabetes prevalence for 2013 and projections for 2035," Diabetes Research and Clinical Practice, vol. 103, no. 2, pp. 137-149, 2014. 
[4] M. B. Weber, R. Oza-Frank, L. R. Staimez, M. K. Ali, and K. M. Venkat Narayan, "Type 2 diabetes in Asians: prevalence, risk factors, and effectiveness of behavioral intervention at individual and population levels," Annual Review of Nutrition, vol. 32, no. 1, pp. 417-439, 2012.

[5] H. S. Kahn and D. F. Williamson, "Race, parity, and gestational diabetes as risk factors for type 2 diabetes mellitus," JAMA, vol. 284, no. 18, pp. 2318-2319, 2000.

[6] X. Rao, J. Montresor-Lopez, R. Puett, S. Rajagopalan, and R. D. Brook, "Ambient air pollution: an emerging risk factor for diabetes mellitus," Current Diabetes Reports, vol. 15, no. 6, p. 603, 2015.

[7] E. V. Balti, J. B. Echouffo-Tcheugui, Y. Y. Yako, and A. P. Kengne, "Air pollution and risk of type 2 diabetes mellitus: a systematic review and meta-analysis," Diabetes Research and Clinical Practice, vol. 106, no. 2, pp. 161-172, 2014.

[8] X. Rao, P. Patel, R. Puett, and S. Rajagopalan, “Air pollution as a risk factor for type 2 diabetes," Toxicological Sciences, vol. 143, no. 2, pp. 231-241, 2015.

[9] E. Samoli, M. Stafoggia, S. Rodopoulou et al., "Which specific causes of death are associated with short term exposure to fine and coarse particles in Southern Europe? Results from the MED-PARTICLES project," Environment International, vol. 67, pp. 54-61, 2014.

[10] J. F. Pearson, C. Bachireddy, S. Shyamprasad, A. B. Goldfine, and J. S. Brownstein, "Association between fine particulate matter and diabetes prevalence in the U.S," Diabetes Care, vol. 33, no. 10, pp. 2196-2201, 2010.

[11] I. C. Eze, E. Schaffner, E. Fischer et al., "Long-term air pollution exposure and diabetes in a population-based Swiss cohort," Environment International, vol. 70, pp. 95-105, 2014.

[12] X. Xu, C. Liu, Z. Xu et al., "Long-term exposure to ambient fine particulate pollution induces insulin resistance and mitochondrial alteration in adipose tissue," Toxicological Sciences, vol. 124, no. 1, pp. 88-98, 2011.

[13] B. Niemann, S. Rohrbach, M. R. Miller, D. E. Newby, V. Fuster, and J. C. Kovacic, "Oxidative stress and cardiovascular risk: obesity, diabetes, smoking, and pollution: part 3 of a 3-part series," Journal of the American College of Cardiology, vol. 70, no. 2, pp. 230-251, 2017.

[14] A. O. Lawal, "Air particulate matter induced oxidative stress and inflammation in cardiovascular disease and atherosclerosis: the role of Nrf2 and AhR-mediated pathways," Toxicology Letters, vol. 270, pp. 88-95, 2017.

[15] B. Messner and D. Bernhard, "Smoking and cardiovascular disease," Arteriosclerosis, Thrombosis, and Vascular Biology, vol. 34, no. 3, pp. 509-515, 2014.

[16] N. Watts, M. Amann, S. Ayeb-Karlsson et al., "The Lancet Countdown on health and climate change: from 25 years of inaction to a global transformation for public health," The Lancet, vol. 391, no. 10120, pp. 581-630, 2018.

[17] R. Basu, D. Pearson, B. Malig, R. Broadwin, and R. Green, "The effect of high ambient temperature on emergency room visits," Epidemiology, vol. 23, no. 6, pp. 813-820, 2012.

[18] M. Z. Wang, S. Zheng, S. L. He et al., "The association between diurnal temperature range and emergency room admissions for cardiovascular, respiratory, digestive and genitourinary disease among the elderly: a time series study," Science of The Total Environment, vol. 456-457, pp. 370-375, 2013.

[19] J. A. Patz, H. Frumkin, T. Holloway, D. J. Vimont, and A. Haines, "Climate change: challenges and opportunities for global health," JAMA, vol. 312, no. 15, pp. 1565-1580, 2014.
[20] J. Li, X. Xu, J. Yang et al., “Ambient high temperature and mortality in Jinan, China: a study of heat thresholds and vulnerable populations," Environmental Research, vol. 156, pp. 657-664, 2017.

[21] T. Sherbakov, B. Malig, K. Guirguis, A. Gershunov, and R. Basu, "Ambient temperature and added heat wave effects on hospitalizations in California from 1999 to 2009," Environmental Research, vol. 160, pp. 83-90, 2018.

[22] L. L. Blauw, N. A. Aziz, M. R. Tannemaat et al., "Diabetes incidence and glucose intolerance prevalence increase with higher outdoor temperature," BMJ Open Diabetes Research \& Care, vol. 5, no. 1, article e000317, 2017.

[23] P. G. Lindqvist, H. Olsson, and M. Landin-Olsson, "Are active sun exposure habits related to lowering risk of type 2 diabetes mellitus in women, a prospective cohort study?", Diabetes Research and Clinical Practice, vol. 90, no. 1, pp. 109-114, 2010.

[24] L. Wang, P. Gao, M. Zhang et al., "Prevalence and ethnic pattern of diabetes and prediabetes in China in 2013," JAMA, vol. 317, no. 24, pp. 2515-2523, 2017.

[25] H. Tian, G. Song, H. Xie, H. Zhang, J. Tuomilehto, and G. Hu, "Prevalence of diabetes and impaired fasting glucose among 769,792 rural Chinese adults," Diabetes Research and Clinical Practice, vol. 84, no. 3, pp. 273-278, 2009.

[26] T. Petäjä, L. Järvi, V.-M. Kerminen et al., "Enhanced air pollution via aerosol-boundary layer feedback in China," Scientific Reports, vol. 6, no. 1, article 18998, 2016.

[27] S. Zhao, Y. Yu, D. Yin et al., "Annual and diurnal variations of gaseous and particulate pollutants in 31 provincial capital cities based on in situ air quality monitoring data from China National Environmental Monitoring Center," Environment International, vol. 86, pp. 92-106, 2016.

[28] L. Wang, F. Zhang, E. Pilot et al., "Taking action on air pollution control in the Beijing-Tianjin-Hebei (BTH) region: progress, challenges and opportunities," International Journal of Environmental Research and Public Health, vol. 15, no. 2, p. 306, 2018.

[29] A. S. Goudie, "Desert dust and human health disorders," Environment International, vol. 63, pp. 101-113, 2014.

[30] K. G. M. M. Alberti, P. Z. Zimmet, and WHO Consultation, "Definition, diagnosis and classification of diabetes mellitus and its complications. Part 1: diagnosis and classification of diabetes mellitus provisional report of a WHO consultation," Diabetic Medicine, vol. 15, no. 7, pp. 539-553, 1998.

[31] J. Zhu, X. Zhang, X. Zhang et al., "The burden of ambient air pollution on years of life lost in Wuxi, China, 2012-2015: a time-series study using a distributed lag non-linear model," Environmental Pollution, vol. 224, pp. 689-697, 2017.

[32] V. C. Pun, L. Tian, I. T. S. Yu, M. A. Kioumourtzoglou, and H. Qiu, "Differential distributed lag patterns of sourcespecific particulate matter on respiratory emergency hospitalizations," Environmental Science \& Technology, vol. 49, no. 6, pp. 3830-3838, 2015.

[33] H. Qiu, C. M. Schooling, S. Sun et al., "Long-term exposure to fine particulate matter air pollution and type 2 diabetes mellitus in elderly: a cohort study in Hong Kong," Environment International, vol. 113, pp. 350-356, 2018.

[34] B. Bowe, Y. Xie, T. Li, Y. Yan, H. Xian, and Z. al-Aly, "The 2016 global and national burden of diabetes mellitus attributable to PM2.5 air pollution," The Lancet Planetary Health, vol. 2, no. 7, pp. e301-e312, 2018. 
[35] U. Krämer, C. Herder, D. Sugiri et al., "Traffic-related air pollution and incident type 2 diabetes: results from the SALIA cohort study," Environmental Health Perspectives, vol. 118, no. 9, pp. 1273-1279, 2010.

[36] T. To, J. Zhu, P. J. Villeneuve et al., "Chronic disease prevalence in women and air pollution-a 30-year longitudinal cohort study," Environment International, vol. 80, pp. 26-32, 2015.

[37] I. C. Eze, L. G. Hemkens, H. C. Bucher et al., “Association between ambient air pollution and diabetes mellitus in Europe and North America: systematic review and meta-analysis," Environmental Health Perspectives, vol. 123, no. 5, pp. 381389, 2015.

[38] M. Renzi, F. Cerza, C. Gariazzo et al., "Air pollution and occurrence of type 2 diabetes in a large cohort study," Environment International, vol. 112, pp. 68-76, 2018.

[39] L. Bai, H. Chen, M. Hatzopoulou et al., "Exposure to ambient ultrafine particles and nitrogen dioxide and incident hypertension and diabetes," Epidemiology, vol. 29, no. 3, pp. 323-332, 2018.

[40] G. Weinmayr, F. Hennig, K. Fuks et al., "Long-term exposure to fine particulate matter and incidence of type 2 diabetes mellitus in a cohort study: effects of total and traffic-specific air pollution," Environmental Health, vol. 14, no. 1, p. 53, 2015.

[41] B. Wang, D. Xu, Z. Jing, D. Liu, S. Yan, and Y. Wang, "Mechanisms in endocrinology: effect of long-term exposure to air pollution on type 2 diabetes mellitus risk: a systemic review and meta-analysis of cohort studies," European Journal of Endocrinology, vol. 171, no. 5, pp. R173-R182, 2014.

[42] L. Tong, K. Li, and Q. Zhou, "The association between air pollutants and morbidity for diabetes and liver diseases modified by sexes, ages, and seasons in Tianjin, China," Environmental Science and Pollution Research, vol. 22, no. 2, pp. 1215-1219, 2015.

[43] Z. Chen, M. T. Salam, C. Toledo-Corral et al., "Ambient air pollutants have adverse effects on insulin and glucose homeostasis in Mexican Americans," Diabetes Care, vol. 39, no. 4, pp. 547-554, 2016.

[44] E. Paoletti, A. Materassi, G. Fasano et al., "A new-generation 3D ozone FACE (Free Air Controlled Exposure)," Science of The Total Environment, vol. 575, pp. 1407-1414, 2017.

[45] M. Jerrett, R. Brook, L. F. White et al., "Ambient ozone and incident diabetes: a prospective analysis in a large cohort of African American women," Environment International, vol. 102, pp. 42-47, 2017.

[46] C. Liu, X. Xu, Y. Bai et al., “Air pollution-mediated susceptibility to inflammation and insulin resistance: influence of CCR2 pathways in mice," Environmental Health Perspectives, vol. 122, no. 1, pp. 17-26, 2014.

[47] C. Liu, Z. Ying, J. Harkema, Q. Sun, and S. Rajagopalan, "Epidemiological and experimental links between air pollution and type 2 diabetes," Toxicologic Pathology, vol. 41, no. 2, pp. 361373, 2013.

[48] S. D. Dubowsky, H. Suh, J. Schwartz, B. A. Coull, and D. R. Gold, "Diabetes, obesity, and hypertension may enhance associations between air pollution and markers of systemic inflammation," Environmental Health Perspectives, vol. 114, no. 7, pp. 992-998, 2006.

[49] X. Wang, W. Bao, J. Liu et al., "Inflammatory markers and risk of type 2 diabetes: a systematic review and meta-analysis," Diabetes Care, vol. 36, no. 1, pp. 166-175, 2012.
[50] Q. Sun, P. Yue, J. A. Deiuliis et al., “Ambient air pollution exaggerates adipose inflammation and insulin resistance in a mouse model of diet-induced obesity," Circulation, vol. 119, no. 4, pp. 538-546, 2009.

[51] S. Gordon, "The macrophage: past, present and future," European Journal of Immunology, vol. 37, Supplement 1, pp. S9S17, 2007.

[52] W. D. van Marken Lichtenbelt, J. W. Vanhommerig, N. M. Smulders et al., "Cold-activated brown adipose tissue in healthy men," The New England Journal of Medicine, vol. 360, no. 15, pp. 1500-1508, 2009.

[53] A. M. Cypess, S. Lehman, G. Williams et al., "Identification and importance of brown adipose tissue in adult humans," The New England Journal of Medicine, vol. 360, no. 15, pp. 1509-1517, 2009.

[54] T. Yoneshiro, S. Aita, M. Matsushita et al., "Recruited brown adipose tissue as an antiobesity agent in humans," The Journal of Clinical Investigation, vol. 123, no. 8, pp. 3404-3408, 2013.

[55] G. Tian, Z. Qiao, and X. Xu, "Characteristics of particulate matter (PM10) and its relationship with meteorological factors during 2001-2012 in Beijing," Environmental Pollution, vol. 192, pp. 266-274, 2014.

[56] B. Altieri, W. B. Grant, S. Della Casa et al., "Vitamin D and pancreas: the role of sunshine vitamin in the pathogenesis of diabetes mellitus and pancreatic cancer," Critical Reviews in Food Science and Nutrition, vol. 57, no. 16, pp. 3472-3488, 2017.

[57] K. C. Chiu, A. Chu, V. L. W. Go, and M. F. Saad, "Hypovitaminosis $\mathrm{D}$ is associated with insulin resistance and beta cell dysfunction," The American Journal of Clinical Nutrition, vol. 79, no. 5, pp. 820-825, 2004.

[58] M. F. Holick and T. C. Chen, "Vitamin D deficiency: a worldwide problem with health consequences," The American Journal of Clinical Nutrition, vol. 87, no. 4, pp. 1080S-1086S, 2008.

[59] J. A. Sugden, J. I. Davies, M. D. Witham, A. D. Morris, and A. D. Struthers, "Vitamin D improves endothelial function in patients with type 2 diabetes mellitus and low vitamin D levels," Diabetic Medicine, vol. 25, no. 3, pp. 320-325, 2008.

[60] J. Schwartz, "The distributed lag between air pollution and daily deaths," Epidemiology, vol. 11, no. 3, pp. 320-326, 2000.

[61] Y. Gu and S. H. L. Yim, "The air quality and health impacts of domestic trans-boundary pollution in various regions of China," Environment International, vol. 97, pp. 117-124, 2016.

[62] E. Lontchi-Yimagou, M. Tsalefac, L. M. T. Tapinmene et al., "Seasonality in diabetes in Yaounde, Cameroon: a relation with precipitation and temperature," BMC Public Health, vol. 16, no. 1, p. 470, 2016.

[63] W. Ouyang, B. Guo, G. Cai et al., "The washing effect of precipitation on particulate matter and the pollution dynamics of rainwater in downtown Beijing," Science of The Total Environment, vol. 505, pp. 306-314, 2015.

[64] J. E. Clougherty, "A growing role for gender analysis in air pollution epidemiology," Environmental Health Perspectives, vol. 118, no. 2, pp. 167-176, 2010.

[65] R. Chen, G. Pan, H. Kan et al., "Ambient air pollution and daily mortality in Anshan, China: a time-stratified casecrossover analysis," Science of The Total Environment, vol. 408, no. 24, pp. 6086-6091, 2010.

[66] J. D. Sacks, L. W. Stanek, T. J. Luben et al., "Particulate matterinduced health effects: who is susceptible?," Environmental Health Perspectives, vol. 119, no. 4, pp. 446-454, 2011. 
[67] S. Vasto, G. Candore, C. R. Balistreri et al., "Inflammatory networks in ageing, age-related diseases and longevity," Mechanisms of Ageing and Development, vol. 128, no. 1, pp. 83-91, 2007.

[68] A. B. Hansen, L. Ravnskjær, S. Loft et al., "Long-term exposure to fine particulate matter and incidence of diabetes in the Danish Nurse Cohort," Environment International, vol. 91, pp. 243-250, 2016.

[69] J. P. Bastard, M. Maachi, C. Lagathu et al., "Recent advances in the relationship between obesity, inflammation, and insulin resistance," European Cytokine Network, vol. 17, no. 1, pp. 4$12,2006$.

[70] S. Nandasena, A. R. Wickremasinghe, K. Lee, and N. Sathiakumar, "Indoor fine particle (PM2.5) pollution exposure due to secondhand smoke in selected public places of Sri Lanka," American Journal of Industrial Medicine, vol. 55, no. 12, pp. 1129-1136, 2012.

[71] L. Dioni, M. Hoxha, F. Nordio et al., "Effects of short-term exposure to inhalable particulate matter on telomere length, telomerase expression, and telomerase methylation in steel workers," Environmental Health Perspectives, vol. 119, no. 5, pp. 622-627, 2011. 